\title{
Population Dynamics and Biological Feasibility of Sustainable Harvesting as a Conservation Strategy for Tropical and Temperate Freshwater Turtles --Manuscript Draft--
}

\begin{tabular}{|c|c|}
\hline Manuscript Number: & PONE-D-19-28843 \\
\hline Article Type: & Research Article \\
\hline Full Title: & $\begin{array}{l}\text { Population Dynamics and Biological Feasibility of Sustainable Harvesting as a } \\
\text { Conservation Strategy for Tropical and Temperate Freshwater Turtles }\end{array}$ \\
\hline Short Title: & Biological Feasibility of Sustainable Harvesting for Freshwater Turtles \\
\hline Corresponding Author: & $\begin{array}{l}\text { Darren Norris, Ph.D. } \\
\text { Universidade Federal de Amapa } \\
\text { Macapa, BRAZIL }\end{array}$ \\
\hline Keywords: & $\begin{array}{l}\text { age; Clutch size; Fecundity; Growth rates; Isotherm; life history; Mortality; survival; } \\
\text { Population Dynamics; Population ecology; Reproduction; Reptile; Sexual maturity; } \\
\text { Sustainable harvest; Turtles }\end{array}$ \\
\hline t. & 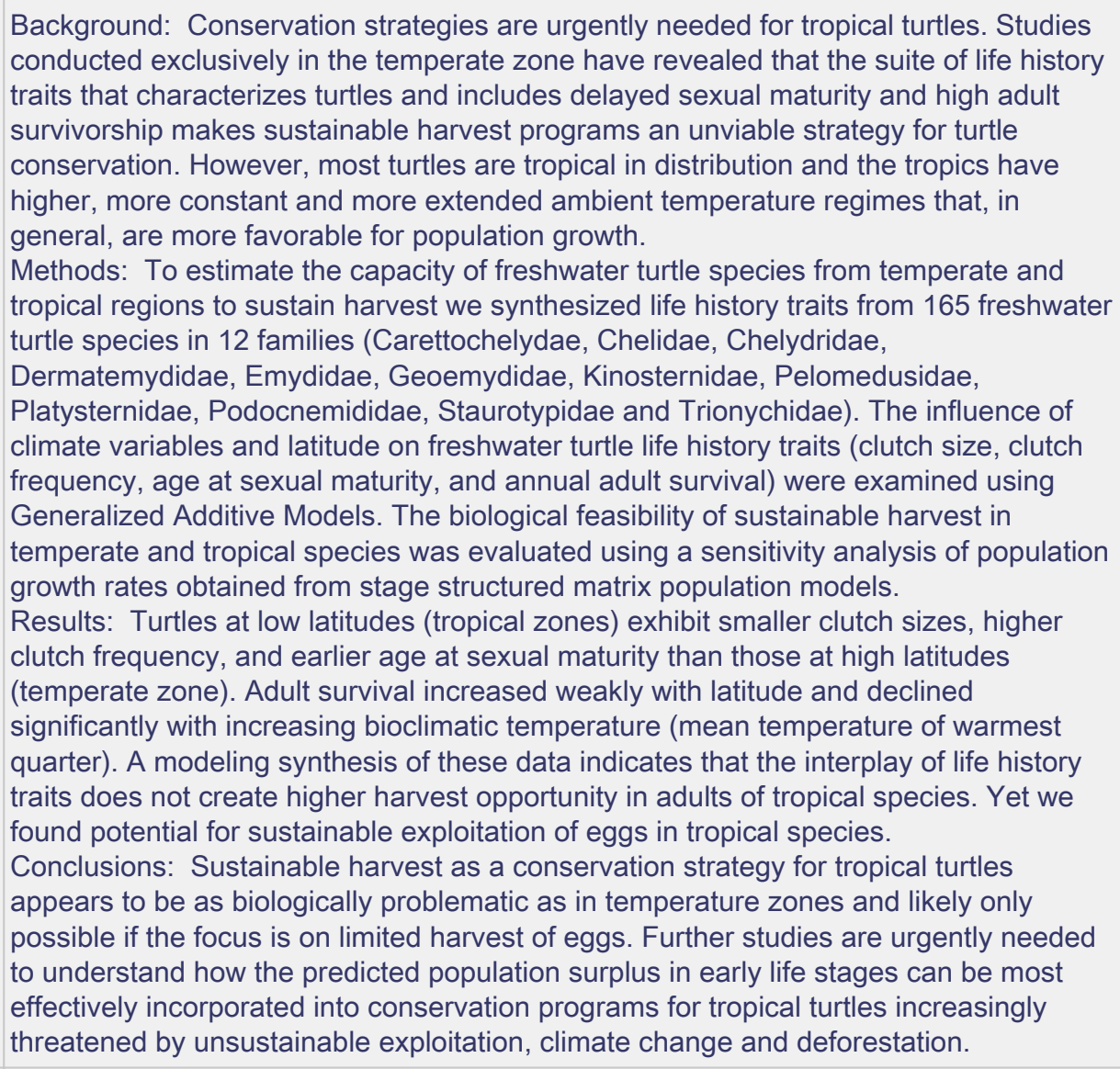 \\
\hline \multirow[t]{3}{*}{ Order of Authors: } & Angga Rachmansah \\
\hline & Darren Norris, Ph.D. \\
\hline & James Peter Gibbs \\
\hline \multicolumn{2}{|l|}{ Additional Information: } \\
\hline Question & Response \\
\hline $\begin{array}{l}\text { Financial Disclosure } \\
\text { Enter a financial disclosure statement that }\end{array}$ & The author(s) received no specific funding for this work. \\
\hline
\end{tabular}


describes the sources of funding for the work included in this submission. Review the submission guidelines for detailed requirements. View published research articles from PLOS ONE for specific examples.

This statement is required for submission and will appear in the published article if the submission is accepted. Please make sure it is accurate.

\section{Unfunded studies}

Enter: The author(s) received no specific funding for this work.

\section{Funded studies}

Enter a statement with the following details:

- Initials of the authors who received each award

- Grant numbers awarded to each author

- The full name of each funder

- URL of each funder website

- Did the sponsors or funders play any role in the study design, data collection and analysis, decision to publish, or preparation of the manuscript?

- NO - Include this sentence at the end of your statement: The funders had no role in study design, data collection and analysis, decision to publish, or preparation of the manuscript.

- YES - Specify the role(s) played.

* typeset

\section{Competing Interests}

The authors have declared that no competing interests exist.

Use the instructions below to enter a competing interest statement for this submission. On behalf of all authors, disclose any competing interests that could be perceived to bias this work-acknowledging all financial support and any other relevant financial or nonfinancial competing interests.

This statement will appear in the published article if the submission is accepted. Please make sure it is accurate. View published research articles from PLOS ONE for specific examples. 


\section{NO authors have competing interests}

Enter: The authors have declared that no competing interests exist.

Authors with competing interests

Enter competing interest details beginning with this statement:

I have read the journal's policy and the authors of this manuscript have the following competing interests: [insert competing interests here]

* typeset

\section{Ethics Statement}

Enter an ethics statement for this submission. This statement is required if the study involved:

- Human participants

- Human specimens or tissue

- Vertebrate animals or cephalopods

- Vertebrate embryos or tissues

- Field research

Write "N/A" if the submission does not require an ethics statement.

General guidance is provided below.

Consult the submission guidelines for detailed instructions. Make sure that all information entered here is included in the Methods section of the manuscript. 


\section{Format for specific study types}

Human Subject Research (involving human participants and/or tissue)

- Give the name of the institutional review board or ethics committee that approved the study

- Include the approval number and/or a statement indicating approval of this research

- Indicate the form of consent obtained (written/oral) or the reason that consent was not obtained (e.g. the data were analyzed anonymously)

\section{Animal Research (involving vertebrate}

\section{animals, embryos or tissues)}

- Provide the name of the Institutional Animal Care and Use Committee (IACUC) or other relevant ethics board that reviewed the study protocol, and indicate whether they approved this research or granted a formal waiver of ethical approval

- Include an approval number if one was obtained

- If the study involved non-human primates, add additional details about animal welfare and steps taken to ameliorate suffering

- If anesthesia, euthanasia, or any kind of animal sacrifice is part of the study, include briefly which substances and/or methods were applied

\section{Field Research}

Include the following details if this study involves the collection of plant, animal, or other materials from a natural setting:

- Field permit number

- Name of the institution or relevant body that granted permission

\section{Data Availability}

Yes - all data are fully available without restriction

Authors are required to make all data underlying the findings described fully available, without restriction, and from the time of publication. PLOS allows rare exceptions to address legal and ethical concerns. See the PLOS Data Policy and FAQ for detailed information. 
A Data Availability Statement describing where the data can be found is required at submission. Your answers to this question constitute the Data Availability Statement and will be published in the article, if accepted.

Important: Stating 'data available on request from the author' is not sufficient. If your data are only available upon request, select 'No' for the first question and explain your exceptional situation in the text box.

Do the authors confirm that all data underlying the findings described in their manuscript are fully available without restriction?

Describe where the data may be found in All relevant data are within the manuscript and its Supporting Information files. full sentences. If you are copying our sample text, replace any instances of $X X X$ with the appropriate details.

- If the data are held or will be held in a public repository, include URLs, accession numbers or DOls. If this information will only be available after acceptance, indicate this by ticking the box below. For example: $A$ II $X X X$ files are available from the $X X X$ database (accession number(s) $X X X, X X X$.).

- If the data are all contained within the manuscript and/or Supporting Information files, enter the following: All relevant data are within the manuscript and its Supporting Information files.

- If neither of these applies but you are able to provide details of access elsewhere, with or without limitations, please do so. For example:

Data cannot be shared publicly because of $[X X X]$. Data are available from the $X X X$ Institutional Data Access / Ethics Committee (contact via $X X X)$ for researchers who meet the criteria for access to confidential data.

The data underlying the results presented in the study are available from (include the name of the third party 
and contact information or URL).

- This text is appropriate if the data are owned by a third party and authors do not have permission to share the data.

* typeset

Additional data availability information: 
1 Title: Population Dynamics and Biological Feasibility of Sustainable Harvesting as a

2 Conservation Strategy for Tropical and Temperate Freshwater Turtles

3 Short title: Biological Feasibility of Sustainable Harvesting for Freshwater Turtles

4 Angga Rachmansah ${ }^{1, \# a,}$, Darren Norris ${ }^{2,3, *}$, James P. Gibbs $^{1}$

$5 \quad{ }^{1}$ Department of Environmental and Forest Biology, State University of New York College of

6 Environmental Science and Forestry, Syracuse, New York, United States of America

$7 \quad{ }^{2}$ Ecology and Conservation of Amazonian Vertebrates Research Group, Federal University of

8 Amapá, Rod. Juscelino Kubitschek Km 02, 68903-419 Macapá, Amapá, Brazil

$9{ }^{3}$ Postgraduate Programme in Tropical Biodiversity, Federal University of Amapá, Rod. Juscelino

10 Kubitschek Km 02, 68903-419 Macapá, Amapá, Brazil

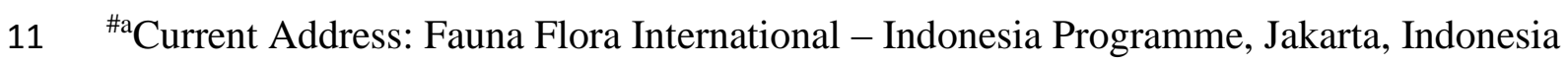

12 *Corresponding author. Coordenação de Ciências Ambientais, Federal University of Amapá,

13 Rod. Juscelino Kubitschek Km 02, 68903-419 Macapá, Brazil. Email: dnorris75@ gmail.com

15 Keywords: Age; Clutch size; Fecundity; Growth rates; Isotherm; Life history; Mortality;

16 Survival; Population dynamics; Population ecology; Reproduction; Reptile; Sexual maturity;

17 Sustainable harvest; Turtles 


\section{Abstract}

Background: Conservation strategies are urgently needed for tropical turtles. Studies conducted exclusively in the temperate zone have revealed that the suite of life history traits that characterizes turtles and includes delayed sexual maturity and high adult survivorship makes sustainable harvest programs an unviable strategy for turtle conservation. However, most turtles are tropical in distribution and the tropics have higher, more constant and more extended ambient temperature regimes that, in general, are more favorable for population growth.

Methods: To estimate the capacity of freshwater turtle species from temperate and tropical regions to sustain harvest we synthesized life history traits from 165 freshwater turtle species in 12 families (Carettochelydae, Chelidae, Chelydridae, Dermatemydidae, Emydidae, Geoemydidae, Kinosternidae, Pelomedusidae, Platysternidae, Podocnemididae, Staurotypidae and Trionychidae). The influence of climate variables and latitude on freshwater turtle life history traits (clutch size, clutch frequency, age at sexual maturity, and annual adult survival) were examined using Generalized Additive Models. The biological feasibility of sustainable harvest in temperate and tropical species was evaluated using a sensitivity analysis of population growth rates obtained from stage structured matrix population models.

Results: Turtles at low latitudes (tropical zones) exhibit smaller clutch sizes, higher clutch frequency, and earlier age at sexual maturity than those at high latitudes (temperate zone). Adult survival increased weakly with latitude and declined significantly with increasing bioclimatic temperature (mean temperature of warmest quarter). A modeling synthesis of these data indicates that the interplay of life history traits does not create higher harvest opportunity in adults of tropical species. Yet we found potential for sustainable exploitation of eggs in tropical species.

Conclusions: Sustainable harvest as a conservation strategy for tropical turtles appears to be as biologically problematic as in temperature zones and likely only possible if the focus is on limited harvest of eggs. Further studies are urgently needed to understand how the predicted population surplus in early life stages can be most effectively incorporated into conservation programs for tropical turtles increasingly threatened by unsustainable exploitation, climate change and deforestation. 


\section{Introduction}

48 Vertebrate animals are important for human welfare and wellbeing [1-3], particularly as food,

49 medicine, and cultural uses by rural and aboriginal communities [3-6]. Freshwater turtles are a

50 good example - they are frequently targeted for both subsistence and commercial harvest,

51 primarily by local communities that live in the vicinity of river and wetlands [7-9]. High biomass

$52[10,11]$, ease of capture, and extended survival with minimal care in captivity make freshwater

53 turtles a focus for harvest [7-9].

Unsustainable harvesting is recognized as one of the major factors driving global

55 freshwater turtle decline [12-15] . Over $40 \%$ of turtle species are endangered as a result of overexploitation $[13,15,16]$. Although turtles are harvested for various purposes (e.g. pets,

57 medicine, and curios), the most heavy use of turtles is for food [7, 16, 17]. Large adult turtles

58 [18-21] and eggs [18] are usually the primary target of harvesting, because these life stages are

59 the most valuable for food $[7,8,16]$ and the easiest life stages to encounter. The greatest

60 harvesting pressure occurs in tropical areas [7, 8] where the most freshwater turtles occur [22].

61 For many local people in these areas, turtle meat and eggs are not only important as sources of

62 protein and lipid, but also support them economically [7, 16, 23]. Additionally, unsustainable

63 exploitation in tropical areas can also lead to regional population collapse and as a consequence

64 create pressures in other regions of the world [24].

Sustainable harvesting programs have been widely promoted as a strategy for wildlife

66 conservation $[25,26]$. Moreover, active involvement of local people in these sustainable harvest

67 programs generally creates better outcomes for conserving wildlife [26, 27]. However, this

68 conservation strategy is assumed not viable for turtle conservation [7, 28]. A corpus of research 
on the topic has revealed that turtles are poor candidates for any sustainable use program [29-31].

70 In general, turtles exhibit delayed sexual maturity, high adult survivorship, low fecundity, and

71 long life span [29-34]. This combination of life history traits limits their ability to compensate for

72 additive adult mortality from harvesting [9, 28, 32, 34, 35].

73

74

75

76

77

78

79

80

81

82

83

84

85

86

87

88

89

90

91

It is notable, however, that virtually all research on sustainability of harvest as a conservation strategy for turtles has been conducted in temperate zones. Variation in life history traits occur within and between turtle species that inhabit different environments [32, 36-40]. Variation in clutch size [36, 41], clutch frequency [33], growth rate, and age at sexual maturity [36] in relation to latitude have been observed in turtles. The interplay of these different life history traits has been suggested to create more opportunity to harvest turtles sustainably, at least in one tropical freshwater species in Northern Australia [19, 42]. Earlier age at sexual maturity, higher fecundity, and faster growth rates in this tropical freshwater turtle compared to other turtles [42] may allow their populations to be harvested at $20 \%$ annual harvest rate [19], suggesting that the widely held assumption of the biological infeasibility of sustainable harvest programs for freshwater turtles based almost entirely on temperate zone species should be reassessed given the challenges of conserving turtles in rapidly developing tropical regions where most turtle diversity occurs [9, 13].

In this study, we investigated global patterns of life history traits (clutch size, clutch frequency, age at sexual maturity, and adult survival) in freshwater turtles using published data and contrasted them between freshwater turtle species from temperate and tropical regions. We then developed a population projection model to estimate the capacity of freshwater turtle species from temperate and tropical regions to sustain harvest. The primary goal of this study was to evaluate the hypothesis that freshwater turtle species from tropical and temperate regions 
92 have the same, widely speculated incapacity to absorb additive mortality caused by population

93 harvest $[29,30,35]$.

95 Materials and Methods

\section{Data Collection}

97 Life history traits of freshwater turtle species were quantified along with locality of each report

98 (latitude and longitude) from the published literature. We used keywords "life history", "clutch

99 size", "clutch frequency", "reproduction", "age at sexual maturity”, "survival”, "growth”,

100 "natural history", and "turtle" to explore the published literature as indexed in the databases of

101 EBSCO, Google Scholar, and Web of Science. The mean, median, or range values of

102 reproductive parameters (clutch size, clutch frequency), demographic parameters (age at sexual

103 maturity, annual adult survival rate), and morphological characters (carapace length) were

104 extracted from each report acquired. Annual adult survival values were also checked and

105 confirmed against those available for 15 freshwater turtle species in an online demographic

106 database COMADRE [43] (version 3.0.0, accessed 2 September 2019 http://www.comadre-

107 db.org/Data/Comadre).

When the exact coordinates of locality were not described, we estimated location from the nearest locality described in a given report. The coordinates of each turtle life history report were

110 also combined with GBIF records (accessed via GBIF.org on 2019-01-13) and published data

111 [38] to establish species distribution across four latitudinal classes: Temperate (species with

112 latitudinal median and range within temperate zone), Temperate-tropical (“Temp-trop", species

113 with latitudinal median within temperate and range overlapping tropical zone/s), Tropical- 
114 temperate ("Trop-temp", species with latitudinal median within tropical and range overlapping

115 temperate zone/s), Tropical (species with latitudinal median and range within tropical zone). The

116 tropics of Capricorn and Cancer (latitude $-23.5^{\circ}, 23.5^{\circ}$, respectively) were used to define

117 geographic limits of temperate and tropical zones.

118 Two bioclimatic variables relevant to freshwater turtle biology, Mean Temperature of

119 Warmest Quarter (bio10, ${ }^{\circ} \mathrm{C}$ ) and Precipitation of Driest Quarter (bio17, mm) were obtained

120 from WorldClim - Global Climate Data (5-arc $\approx 10 \mathrm{~km}$ resolution, www.worldclim.org, [44])

121 and matched to the coordinates of each turtle life history report. These bioclimatic variables were

122 selected as proxies to represent the metabolic, physiological and behavioral differences that

123 freshwater turtles have developed to survive in regions that are not ideal for these temperature

124 and water dependent species $[10,22,32,33,38-41,45]$. Both bioclimatic variables were only

125 weakly correlated with latitude (Spearmans correlation 0.40 and 0.04 for bio10 and bio17

126 respectively) and were therefore included to represent temperature and rainfall patterns distinct

127 to those most strongly associated with latitudinal gradients.

\section{Statistical Analysis}

129 We used Generalized Additive Models (GAMs, [46, 47]) to examine the influence of climate

130 variables and latitude on freshwater turtle life history traits (clutch size, clutch frequency, age at

131 sexual maturity, and annual adult survival). We treated each freshwater turtle species as a

132 replicate in this analysis (obtaining median life history values within species for species with $n>$

1331 reports) to avoid the pitfalls of pseudoreplication associated with treating individual reports as

134 replicates. Because comparative life history studies are not independent from phylogenetic

135 relationships among turtles, which can lead to phylogenetic bias on inference and trait value 
136 estimation, we treated taxonomic family as a random effect (penalized smoothed regression 137 term) $[48,49]$ based on the Turtles of the World Checklist ( $8^{\text {th }}$ edition, [50]). In addition, we 138 used carapace length (ln-transformed) as a parametric term to control for its well-established 139 influence on life history traits $[33,36,38,41]$.

A total of four models were developed for each life history trait: latitude as a continuous

141 variable included as a parametric term, latitude as a categorical variable with four classes

142 (Temperate, Temp-Trop, Trop-Temp and Tropical), and two bioclimatic variables (Mean 143 Temperature of Warmest Quarter and Precipitation of Driest Quarter) included as parametric 144 terms. All life history trait estimates were ln-transformed, except for adult survival (arcsine 145 transformed). The mgcv package [46] was used to perform the GAM analysis in R (www.r146 project.org, [51]). Akaike Information Criterion corrected for small sample sizes (AICc) that 147 measures fit versus complexity of a model was used to select "best" models based on lowest 148 AICc $[52,53]$.

\section{Modelling Synthesis}

151 To evaluate whether freshwater turtle species from tropical and temperate zones have

152 comparable capacities to absorb additive mortality caused by population harvest, we

153 implemented a density-independent, stage structured "Lefkovitch" matrix population model [34,

$15454,55]$. This type of model is commonly used in turtle population dynamics modelling, as age in 155 most turtle species is often difficult to determine $[19,34]$. The model consisted of egg, juvenile, 156 and adult stages (Fig 1) projected with a stable stage distribution (with an initial population of 157 1000, allocated in proportions of $0.544,0.401,0.055$ to egg, juvenile and adult stages 
158 respectively). The discrete stage based lifecycle (Fig 1) can be presented as a population

159 projection matrix " $A$ " as follows:

160

$$
\boldsymbol{A}=\left[\begin{array}{ccc}
0 & 0 & F \\
G_{1} & P_{1} & 0 \\
0 & G_{2} & P_{2}
\end{array}\right]
$$

161 where $P$ is the annual probability of surviving and remaining in the same stage, $G$ is the annual 162 probability of surviving and growing into next stage, and $F$ is the annual fecundity. These 163 parameters were estimated using the following equations [56]:

164

$$
\begin{aligned}
& P=\frac{\left(1-p_{i}^{d_{i}-1}\right)}{\left(1-p_{i}^{d_{i}}\right)} p_{i} \\
& G=\frac{p_{i}^{d_{i}}\left(1-p_{i}\right)}{1-p_{i}^{d_{i}}}
\end{aligned}
$$

Equation 1

Equation 2

166 where $p_{i}$ is the annual survival probability of $i$ stage and $d_{i}$ is the duration of $i$ stage. Annual

167 fecundity $(F)$ was estimated by multiplying clutch size with clutch frequency. The model was

168 based on female fraction only; thus half of all eggs produced was assumed to be female [29, 30] .

169 The stable distributions of individuals amongst stage classes, and intrinsic rate of population

170 growth $(r)$ were determined with functions available in the R [51] packages "popdemo" [57] and

171 “popbio" [58].

172

173 Fig 1. Conceptual diagram of population dynamics of freshwater turtles used for

174 construction of a stage structure matrix model to estimate capacity for sustainable harvest

175 in freshwater turtles. 
177 Median values of clutch size, clutch frequency, age at sexual maturity and adult survival 178 derived from the GAM predictions was used as input for this stage-structured model. Due to the 179 sparsity of records for some traits (e.g. adult survival) predictions were aggregated across two 180 latitudinal classes (temperate and tropical) to compare the intrinsic rate of population growth $(r)$ 181 between stages and latitude. Predictions for each trait were obtained from a final model that 182 included all variables in a 95\% confidence subset of models [52]. This confidence set was 183 obtained by summing the Akaike weights of the set of all candidate models ordered by Akaike 184 weight from largest to smallest until a sum of $\geq 0.95$ was obtained ([52] pp. 169, 176-177). We 185 estimated the annual survival probability of juvenile stage as $13 \%$ less than the annual survival 186 probability of adult stage [59]. Due to lack of available nest / hatchling survival data the annual 187 survival probability of egg stage for all turtle species was set at $0.2[29,30,32]$. To simulate the 188 impact of harvest on populations of tropical and temperate freshwater turtle species, we 189 performed a sensitivity analysis by varying each demographic parameter systematically while 190 holding all other parameters constant [29, 30]. In addition, we performed Jackknife 191 randomizations [60] drawing deviates $(n=500$ iterations) for each model parameter from the 192 distributions observed in the literature (S1 Table) for these variables to estimate confidence 193 intervals around the estimated intrinsic rates of growth of temperate and tropical species in 194 sensitivity analysis.

Table 1. Demographic parameters in freshwater turtles. Demographic parameters used in 196 population modelling to estimate capacity for sustainable harvest in freshwater turtles. Estimates 197 are median values derived from the scientific literature (S1 Table) and summarized based on the 198 species distributions across four latitudinal classes. 


\begin{tabular}{lcccccccc}
\hline Distribution $^{\mathbf{a}}$ & Families & Species & Lat $^{\mathbf{b}}$ & $\begin{array}{c}\text { Carapace } \\
\text { Length }\end{array}$ & $\begin{array}{c}\text { Clutch } \\
\text { Size }\end{array}$ & $\begin{array}{r}\text { Clutch } \\
\text { Frequency }\end{array}$ & $\begin{array}{r}\text { Age at } \\
\text { sexual } \\
\text { maturity }\end{array}$ & Fecundity \\
\hline Temperate & 6 & 41 & 34.0 & 181.0 & 8.4 & 2.0 & 8.7 & 7.8 \\
Temp-Trop & 6 & 43 & 29.1 & 221.7 & 11.2 & 1.7 & 8.3 & 6.6 \\
Trop-Temp & 10 & 37 & 18.3 & 197.3 & 6.1 & 2.5 & 6.5 & 6.0 \\
Tropical & 10 & 44 & 9.6 & 231.5 & 7.3 & 2.0 & 9.0 & 3.5 \\
Overall & 12 & 164 & 23.1 & 208.0 & 8.0 & 2.0 & 8.3 & 6.3 \\
\hline
\end{tabular}

${ }^{a}$ Distribution of freshwater turtles in four latitudinal classes: Temperate (species latitudinal median and range within temperate zone), Temp-trop (species latitudinal median within temperate and range overlapping tropical zone/s), Trop-temp (species latitudinal median within tropical and range overlapping temperate zone/s), Tropical (species latitudinal median and range within tropical zone). This classification is unique for each species i.e. a species is only included in one class.

${ }^{\mathrm{b}}$ Median latitude from species locations within each distribution class.

\section{Results}

A total of 461 reports of life history traits was obtained from 165 species (63\% of living freshwater turtle species) among 12 taxonomic families (Fig 2, S1 Table). The data once aggregated represent: 84 species from 7 families in the temperate zone (Temperate and Temperate-Tropical classes) and 81 species from 12 families in the tropical zone (TropicalTemperate and Tropical classes). Sixty percent of these studies were from temperate areas, with most of these (73\%) from North America (Fig 2). Forty percent of these data were from tropical areas, with most of these (36\%) from Asia. Only 12 of these life history trait reports were from captive breeding situations while the remainder were from wild populations.

Fig 2. Distribution of freshwater turtle studies. Geographic distribution of data on freshwater turtle life history traits obtained from the literature (S1 Table) to estimate capacity for sustainable harvest in freshwater turtles. Color of study locations represent the distribution of the study 
species across four latitudinal classes: Temperate (species with latitudinal median and range within temperate zone), "Temp-Trop" (species with latitudinal median within temperate and range overlapping tropical zone/s), "Trop-Temp" (species with latitudinal median within tropical and range overlapping temperate zone/s), Tropical (species with latitudinal median and range within tropical zone). Dashed horizontal lines show Tropic of Cancer and Tropic of Capricorn (latitude $-23.5^{\circ}, 23.5^{\circ}$, respectively). The background map was obtained from the $1: 110 \mathrm{~m}$ Natural Earth country and geographic lines maps (http://www.naturalearthdata.com).

Latitude as continuous variable significantly influenced all life history traits, except adult

survival (Table 2, Table 3). Indeed, latitude was the most informative variable for clutch size,

clutch frequency and age at sexual maturity (Table 3$)$. Natural logarithm of clutch size $(\beta=0.13$;

$P<0.001)$ and age at sexual maturity $(\beta=0.06 ; P<0.01)$ were positively related to latitude,

whereas natural logarithm of clutch frequency $(\beta=-0.09 ; P<0.05)$ exhibited a negative

relationship with latitude (Fig 1, Table 2). When latitude was treated as categorical variable, only

the natural logarithm of clutch size was significantly related to latitudinal zones, such that

Tropical $(\beta=-0.21 ; P<0.001)$ and Tropical-Temperate $(\beta=-0.13 ; P<0.05)$ species had

reduced clutch size relative to temperate species (Table 2).

Fig 3. Relationships between latitude and (A) clutch size, (B) clutch frequency, (C) age at sexual maturity, and (D) adult survival rate of freshwater turtles. Points are the median species values obtained from the literature (S1Table), colored representing ln carapace length values. Solid black line is the GAM prediction. Grey shaded polygons show $95 \%$ confidence bands around the prediction.

Of the two bioclimatic variables assessed, only bioclimatic temperature (Mean

Temperature of Warmest Quarter) was a contributor to life history variation (Table 2) and was also the most informative variable for adult survival (Table 3). The bioclimatic temperature models were included in the $95 \%$ confidence set for all life history traits, except clutch size (Table 3$)$. Natural logarithm of age at sexual maturity $(\beta=-0.06 ; P<0.01)$ and arcsine adult 
survival $(\beta=-0.08 ; P<0.05)$ were both negatively related to Mean Temperature of Warmest Quarter (Fig 4).

Fig 4. Relationships between bioclimatic temperature (Mean Temperature of Warmest Quarter) and (A) clutch size, (B) clutch frequency, (C) age at sexual maturity, and (D) adult survival rate of freshwater turtles. Points are the median species values obtained from the literature (S1 Table), colored representing ln carapace length values. Solid black line is the GAM prediction. Grey shaded polygons show $95 \%$ confidence bands around the prediction.

The sensitivity analysis performed to examine the impact of harvest on freshwater turtle populations revealed that adult and juvenile survival rates had dramatically more impact on intrinsic rate of population growth than egg survival rate and fecundity (Fig 5). Tropical freshwater turtle species exhibited a moderately higher intrinsic rate of growth than temperate freshwater turtle species (Fig 5). Although, fecundity tended to be less in tropical species (Table 2, Table 4), comparing the minimum values necessary to result in positive population growth with GAM predictions showed that fecundity could be reduced by $28 \%$ in tropical compared with only $12 \%$ in temperate species (Table 4). Survival rates were estimated to be reducible by $35 \%$ in eggs, $24 \%$ in juveniles, and $5 \%$ in adults for tropical species, and $15 \%, 16 \%$, and $7 \%$, respectively for temperate species, without causing negative population growth (Table 4). However, overlap in estimations of population growth in relation to survival rates was very broad between tropical and temperate turtle species suggesting that, in aggregate the capacity for sustainable harvest of adults as an additive source of turtle mortality is constrained in tropical turtle species largely as it is in temperate zone species (Fig 5, Table 4). 
273 Fig 5. Relationships between intrinsic rate of growth (r) and survival rates of (A) egg, (B)

274 juvenile, and (C) adult, and (D) fecundity in freshwater turtles of tropical and temperate

275 zones. Solid lines are the intrinsic rate of growth for temperate and tropical species, respectively.

276

277 
279 Generalized Additive Models were used to predict responses of four freshwater turtle life history

280 traits: clutch size, clutch frequency, age at sexual maturity and adult survival.

\begin{tabular}{|c|c|c|c|c|c|c|c|c|c|c|c|c|}
\hline \multirow[b]{2}{*}{ Continuous latitude } & \multicolumn{3}{|c|}{ In clutch size $(n=165)$} & \multicolumn{3}{|c|}{$\begin{array}{c}\text { In clutch } \\
\text { frequency }(n= \\
102)\end{array}$} & \multicolumn{3}{|c|}{$\begin{array}{l}\text { In age at sexual } \\
\text { maturity }(n=75)\end{array}$} & \multicolumn{3}{|c|}{$\begin{array}{c}\text { arcsine adult } \\
\text { survival }(n=37)\end{array}$} \\
\hline & Est. ${ }^{a}$ & SE & $p$ & Est. ${ }^{a}$ & SE & $p$ & Est. $^{a}$ & SE & $p$ & Est. $^{a}$ & SE & $p$ \\
\hline Intercept & 0.78 & 0.05 & $* * *$ & 0.12 & 0.05 & $*$ & 0.75 & 0.02 & $* * *$ & 0.12 & 0.03 & $* * *$ \\
\hline Log carapace length & 0.29 & 0.02 & $* * *$ & 0.01 & 0.03 & & 0.09 & 0.02 & $* * *$ & 0.01 & 0.03 & \\
\hline Latitude & 0.13 & 0.00 & $* * *$ & -0.09 & 0.04 & $*$ & 0.06 & 0.02 & $* *$ & 0.04 & 0.03 & \\
\hline Smooth & Edf/ref & $\mathbf{F}$ & $p$ & Edf/ref & $\mathbf{F}$ & $p$ & Edf/ref & $\mathbf{F}$ & $p$ & Edf/ref & $\mathbf{F}$ & $p$ \\
\hline Family & $8.1 / 11$ & 6.48 & $* * *$ & $5.0 / 11$ & 1.2 & $*$ & $0.0 / 10$ & 0.0 & & $0.0 / 7$ & 0.0 & \\
\hline $\mathrm{R}^{2}$ ajust / Dev. $\operatorname{Exp}^{\mathrm{b}}$ & \multicolumn{3}{|c|}{$0.78 / 77.6 \%$} & \multicolumn{3}{|c|}{$0.12 / 17.9 \%$} & \multicolumn{3}{|c|}{$0.19 / 20.2$} & \multicolumn{3}{|c|}{$0.01 / 6.7$} \\
\hline Categorical latitude & Est. $^{a}$ & SE & $p$ & Est. $^{a}$ & SE & $p$ & Est. $^{a}$ & SE & $p$ & Est. $^{a}$ & SE & $p$ \\
\hline Intercept & 0.85 & 0.06 & $* * *$ & 0.12 & 0.06 & - & 0.76 & 0.05 & $* * *$ & 0.10 & 0.06 & \\
\hline Log carapace length & 0.29 & 0.02 & $* * *$ & 0.01 & 0.03 & & 0.06 & 0.03 & $*$ & -0.01 & 0.04 & \\
\hline Latitude temp-trop & 0.04 & 0.05 & & -0.06 & 0.08 & & 0.02 & 0.05 & & 0.08 & 0.06 & \\
\hline trop-temp & -0.13 & 0.05 & $*$ & 0.06 & 0.09 & & -0.11 & 0.07 & & 0.07 & 0.09 & \\
\hline tropical & -0.21 & 0.05 & $* * *$ & 0.04 & 0.09 & & -0.02 & 0.08 & & -0.05 & 0.12 & \\
\hline Smooth & Edf/ref & $\mathbf{F}$ & $p$ & Edf/ref & $\mathbf{F}$ & $p$ & Edf/ref & $\mathbf{F}$ & $p$ & Edf/ref & $\mathbf{F}$ & $p$ \\
\hline Family & $7.9 / 11$ & 6.27 & $* * *$ & $2.7 / 11$ & 0.4 & & $4.7 / 10$ & 0.9 & . & $2.5 / 7$ & 0.6 & \\
\hline $\mathrm{R}^{2}$ ajust / Dev. $\operatorname{Exp}^{\mathrm{b}}$ & \multicolumn{3}{|c|}{$0.76 / 75.8 \%$} & \multicolumn{3}{|c|}{$0.03 / 9.3 \%$} & \multicolumn{3}{|c|}{$0.24 / 32.2 \%$} & \multicolumn{3}{|c|}{$0.07 / 23.8 \%$} \\
\hline Bioclimate - temp & Est. $^{a}$ & SE & $p$ & Est. $^{a}$ & SE & $p$ & Est. $^{a}$ & SE & $p$ & Est. $^{a}$ & SE & $p$ \\
\hline Intercept & 0.76 & 0.05 & $* * *$ & 0.12 & 0.04 & $* *$ & 0.72 & 0.04 & $* * *$ & 0.11 & 0.03 & $* *$ \\
\hline Log carapace length & 0.27 & 0.02 & $* * *$ & 0.01 & 0.03 & & 0.07 & 0.03 & $* *$ & 0.02 & 0.03 & \\
\hline Temp. warm quarter (bio10) & -0.01 & 0.02 & & 0.03 & 0.03 & & -0.06 & 0.02 & $* *$ & -0.08 & 0.03 & $*$ \\
\hline Smooth & Edf/ref & $\mathbf{F}$ & $p$ & Edf/ref & $\mathbf{F}$ & $p$ & Edf/ref & $\mathbf{F}$ & $p$ & Edf/ref & $\mathbf{F}$ & $p$ \\
\hline
\end{tabular}




\begin{tabular}{|c|c|c|c|c|c|c|c|c|c|c|c|c|}
\hline Family & $7.0 / 11$ & 4.39 & $* * *$ & $3.4 / 11$ & 0.6 & & $5.4 / 10$ & 1.2 & $*$ & $0.0 / 7$ & 0.0 & \\
\hline $\mathrm{R}^{2}$ ajust / Dev. Exp ${ }^{\mathrm{b}}$ & \multicolumn{3}{|c|}{$0.72 / 69.8 \%$} & \multicolumn{2}{|c|}{$0.05 / 9.9 \%$} & \multicolumn{3}{|c|}{$0.31 / 37.7 \%$} & \multicolumn{4}{|c|}{$0.12 / 16.7 \%$} \\
\hline Bioclimate - rain & Est. ${ }^{a}$ & SE & $p$ & Est. ${ }^{a}$ & SE & $p$ & Est. $^{a}$ & SE & $p$ & Est. $^{a}$ & SE & $p$ \\
\hline Intercept & 0.76 & 0.05 & $* * *$ & 0.12 & 0.04 & $* *$ & 0.73 & 0.05 & $* * *$ & 0.15 & 0.03 & $* * *$ \\
\hline Log carapace length & 0.27 & 0.02 & $* * *$ & 0.01 & 0.03 & & 0.06 & 0.03 & $*$ & -0.01 & 0.03 & \\
\hline Rain dry quarter (bio17) & -0.03 & 0.02 & & 0.02 & 0.03 & & 0.00 & 0.02 & & 0.02 & 0.04 & \\
\hline Smooth & Edf/ref & $\mathbf{F}$ & $p$ & Edf/ref & $\mathbf{F}$ & $p$ & Edf/ref & $\mathbf{F}$ & $p$ & Edf/ref & $\mathbf{F}$ & $p$ \\
\hline Family & $7.4 / 11$ & 5.71 & $* * *$ & $2.5 / 11$ & 0.3 & & $5.7 / 10$ & 1.5 & $*$ & $0.0 / 7$ & 0.0 & \\
\hline $\mathrm{R}^{2}$ ajust / Dev. $\operatorname{Exp}^{\mathrm{b}}$ & \multicolumn{3}{|c|}{$0.72 / 70.5 \%$} & \multicolumn{2}{|c|}{$0.02 / 7.0 \%$} & \multicolumn{4}{|c|}{$0.24 / 31.6 \%$} & \multicolumn{3}{|c|}{$-0.04 / 1.4 \%$} \\
\hline
\end{tabular}

Each model contained Family as a random effect (smooth GAM term specified with "re" basis) and body size (ln transformed carapace length) as a parametric term; Asterisks indicate significant level of estimated parameters $(* * * P<0.001$; ** $P<0.01$; * $P<0.05$; ' ' $P<0.1$ ).

${ }^{a}$ Standardized regression coefficient (obtained by dividing the centered response values by their standard deviations) and associated standard error (SE).

${ }^{\mathrm{b}}$ Model adjusted r-squared and deviance explained (\%) 
Table 3. Freshwater turtle life history model comparisons. Comparisons of the Generalized

289

290

291

\begin{tabular}{|c|c|c|c|c|c|c|c|}
\hline Life history trait & Model $^{\mathrm{a}}$ & $\begin{array}{l}\text { Dev. } \\
\text { Exp }\end{array}$ & Loglik & $\mathrm{BIC}$ & $\mathrm{AICc}$ & $\begin{array}{l}\Delta \\
\mathrm{AICc}\end{array}$ & $\begin{array}{l}\mathrm{W}_{\mathrm{i}} \\
\mathrm{AICc}^{\mathrm{b}}\end{array}$ \\
\hline \multicolumn{8}{|l|}{ Clutch size } \\
\hline & Continuous latitude & 77.6 & -69.35 & 207.05 & 168.09 & 0.00 & 1.00 \\
\hline & Categorical latitude & 75.8 & -80.04 & 237.57 & 193.80 & 25.71 & 0.00 \\
\hline & Bioclimate - rain & 69.8 & -95.48 & 256.12 & 218.85 & 50.77 & 0.00 \\
\hline & Bioclimate - temp & 70.5 & -98.96 & 261.27 & 224.98 & 56.90 & 0.00 \\
\hline \multicolumn{8}{|l|}{ Clutch frequency } \\
\hline & Continuous latitude & 17.9 & -14.42 & 81.83 & 54.94 & 0.00 & 0.93 \\
\hline & Bioclimate - temp & 9.9 & -19.25 & 85.31 & 61.22 & 6.28 & 0.04 \\
\hline & Bioclimate - rain & 7.0 & -21.01 & 83.69 & 62.00 & 9.79 & 0.03 \\
\hline & Categorical latitude & 9.3 & -19.61 & 91.34 & 64.84 & 12.62 & 0.01 \\
\hline \multicolumn{8}{|l|}{$\begin{array}{l}\text { Age at sexual } \\
\text { maturity }\end{array}$} \\
\hline & Continuous latitude & 20.2 & -28.82 & 79.24 & 68.52 & 0.00 & 0.57 \\
\hline & Bioclimate - temp & 37.7 & -19.46 & 92.49 & 69.13 & 0.62 & 0.42 \\
\hline & Bioclimate - rain & 31.6 & -22.86 & 99.50 & 76.08 & 7.56 & 0.01 \\
\hline & Categorical latitude & 32.2 & -22.62 & 104.54 & 79.42 & 10.91 & 0.00 \\
\hline \multicolumn{8}{|l|}{ Adult survival } \\
\hline & $\begin{array}{l}\text { Bioclimate - temp } \\
\text { Continuous latitude }\end{array}$ & $\begin{array}{r}16.7 \\
6.7\end{array}$ & $\begin{array}{l}14.16 \\
12.09\end{array}$ & $\begin{array}{r}-10.39 \\
-6.27\end{array}$ & $\begin{array}{l}-16.31 \\
-12.19\end{array}$ & $\begin{array}{l}0.00 \\
4.12\end{array}$ & $\begin{array}{l}0.85 \\
0.11\end{array}$ \\
\hline & Bioclimate - rain & 1.4 & 11.09 & -4.26 & -10.18 & 6.13 & 0.04 \\
\hline & Categorical latitude & 23.8 & 15.77 & 7.28 & 0.73 & 17.04 & 0.00 \\
\hline
\end{tabular}

292

293

294

295

296

297

298

299

300

301

302

303

304

305

Additive Models created for each life history trait to estimate capacity for sustainable harvest in

freshwater turtles. Models for each trait ordered by decreasing AICc (Akaike information

criterion corrected for small sample sizes) values.

\footnotetext{
${ }^{a}$ Models used to predict natural history traits. Each model contained Family as a random effect (smooth
} term with "re" basis) and body size (log transformed carapace length) as a parametric (not smooth) effect. Continuous latitude included median latitude from all records (Table S1). Categorical latitude included four latitudinal classes: Temperate (species with latitudinal median and range within temperate zone), "Temp-Trop" (species with latitudinal median within temperate and range overlapping tropical zone/s), "Trop-Temp" (species with latitudinal median within tropical and range overlapping temperate zone/s), Tropical (species with latitudinal median and range within tropical zone). Bioclimate - temp included Mean Temperature of Warmest Quarter (WorldClim: bio10). Bioclimate - rain included Precipitation of Driest Quarter (WorldClim: bio17). Coefficients for individual variables in all models are presented in Table 2.

${ }^{\mathrm{b}}$ Akaike weights $\left(\mathrm{W}_{\mathrm{i}}\right)$ from largest to smallest. Predictions for each trait were obtained using variables from the $95 \%$ confidence subset of models, obtained by first ordering all models in the set by decreasing Akaike weight $\left(\mathrm{W}_{\mathrm{i}}\right)$, and then sequentially summing the model $\mathrm{W}_{\mathrm{i}}$ 's in rank order. 
324 species.

Table 4. Demographic parameters used in population modelling to estimate capacity for sustainable harvest in freshwater turtles. Observed are median values derived from the scientific literature (S1 Table) and predicted values are from the 95\% confidence set of GAM models (Table 3). " $r$ min" are the minimum values necessary to obtain positive intrinsic rate of growth $(r)$ as determined via sensitivity analysis (Fig 5).

\begin{tabular}{lrrrrrr}
\hline \multicolumn{1}{c}{ Parameter } & \multicolumn{2}{c}{ Observed } & \multicolumn{2}{c}{ Predicted } & \multicolumn{2}{c}{$\boldsymbol{r}$ min } \\
& \multicolumn{1}{c}{ Temp. } & \multicolumn{1}{c}{ Trop. } & \multicolumn{1}{c}{ Temp. } & \multicolumn{1}{c}{ Trop. } & \multicolumn{1}{c}{ Temp. } & \multicolumn{1}{c}{ Trop. } \\
\hline Annual egg survival rate & $0.200^{\mathrm{a}}$ & $0.200^{\mathrm{a}}$ & $0.200^{\mathrm{a}}$ & $0.200^{\mathrm{a}}$ & 0.170 & 0.130 \\
Annual juvenile survival rate & $0.766^{\mathrm{b}}$ & $0.767^{\mathrm{b}}$ & $0.746^{\mathrm{b}}$ & $0.694^{\mathrm{b}}$ & 0.630 & 0.530 \\
Annual adult survival rate & 0.880 & 0.882 & 0.857 & 0.798 & 0.800 & 0.760 \\
Clutch size & 8.8 & 7.0 & 7.3 & 5.2 & & \\
Clutch frequency & 2.0 & 2.3 & 2.0 & 2.3 & & \\
Age at sexual maturity & 8.3 & 7.8 & 8.6 & 7.3 & & \\
Fecundity & 7.3 & 6.0 & 7.3 & 6.0 & 6.4 & 4.3 \\
\hline a a & 7.3 & & & & &
\end{tabular}

${ }^{\mathrm{a}}$ Values derived from previous syntheses [32].

${ }^{\mathrm{b}}$ Estimated as $13 \%$ less than the annual adult survival rates [59].

\section{Discussion}

The capacity of any species to cope with additive mortality is determined by the interplay of its life history traits [61-63]. Turtles are often declared to share integrated life history features [64] that make compensation for additive mortality associated with harvest infeasible [28]. Life history traits of many organisms are related to variation in environment [65, 66], climate [67] and their ecological interactions $[61-63,68,69]$ and this study revealed that turtle life history is strongly related to latitude and ambient temperature. Yet although these trends might suggest an increase in capacity of tropical freshwater turtles to absorb additional mortality due to anthropogenic sources than in temperate zone species, once integrated in a synthetic population model tropical species appear to be as unable to absorb additive mortality as are temperate zone 
The positive relationship we observed between clutch size and latitude is consistent with 337 than tropical species [33].

earlier studies [36, 41]. Turtles that inhabit higher (temperate) latitudes, have larger clutch size than turtles that inhabit low (tropical) latitudes. Similar patterns have been observed in mammals [67] and birds [68, 70]. Tokolyi, Schmidt (67) and McNamara, Barta (68) suggest this pattern is related to climate variability. Iverson, Balgooyen (41) concluded that higher juvenile competition due to shorter time period for development along with higher egg mortality associated with winter and climate uncertainty that creates temporary periods of low competition may make it more advantageous for temperate turtle species to produce more offspring ("more eggs in one basket" [33]) as a "bet hedging" strategy to exploit temporary resources. In addition, temperate turtle species typically have small egg size to speed development as an adaptation to short incubation times in temperate zone $[17,41]$. As such, our findings support the suggestion that temperature zone turtles may have evolved to produce smaller egg size with larger clutch size

Larger clutch size in temperate turtle species may also act as a mechanism to compensate for low nesting frequency $[33,41]$. We found that clutch frequency was negatively related to latitude. The general model of the interaction of environmental factors and reproductive output in turtles [33] suggests that high latitudes yield short reproductive seasons for turtles, resulting in lower clutch frequency. In addition, timing of nesting in turtles is correlated with temperature $[36,71]$. Because tropical zones have a more stable warmer temperature all year long, more opportunities are available for turtles to lay eggs than in the temperate zone. Additionally, clutch mass (number of eggs x egg size) can also vary with latitude [33, 41], further studies are necessary to examine how egg size correlates to differences in population growth rates, 
347 especially as egg size has been shown to be an important predictor of age at sexual maturity [32, $34833]$.

The relationship between age at sexual maturity and latitude observed in this study is also 350 in agreement with the earlier studies [72-74]. Turtles that inhabit high latitudes reach maturity at 351 a later age than those inhabit low latitudes. This result is likely due to more stable and more 352 productive climate conditions at low latitudes. As growth rate in turtles depends on temperature 353 and food availability [75, 76], thus stable warm temperature and continuous food availability in 354 low latitudes will generate faster growth rate to reach size at sexual maturity [33]. This 355 conclusion is also supported by the inverse relationship between Mean Temperature of Warmest 356 Quarter and age at sexual maturity. Although it has been suggested that turtles tend to have 357 larger body size at higher latitudes $\lceil 771$ a recent review (compilation of 245 species) failed to 358 uncover clear latitudinal trends in turtle body size [38]. These differences between studies (for 359 example [77] evaluated variation within species from a sample of 23 species of mainly northern 360 hemisphere and temperate turtles) seem to support the hypothesis that body size latitude 361 relationships (e.g. Bergmann's rule) maybe stronger for temperate turtle species. Large body size 362 is thought to provide evolutionary advantages for temperate turtle species to cope with 363 unfavorable environments e.g. via a relative increase in fasting endurance [36, 76]. As a result, 364 temperate turtle species require longer time to reach size at sexual maturity, but increased size 365 may provide for increased adult survivorship [32].

Adult survival and latitude were not strongly related perhaps because all turtles share in 367 common the unique morphological feature: a rigid shell $[28,78,79]$. Turtle shells not only 368 provide physical protection from predators [28], but also important physiological functions [78369 80]. The optimum benefits from the shell are achieved when a turtle has reached adult size [28] 
370 such that different environmental conditions at low and high latitudes may have little effect on

371 adult survival rate because the shell ensures high survival regardless of ecological context.

372

373

374

375

376

377

378

It is important to note, however, that our failure to identify differences in survival rates may result from a lack of statistical power $[53,81]$. Relatively few reports were available for survival rates of turtles at low (tropical) latitudes thereby possibly limiting the ability to detect differences might they exist. Clearly more long-term studies of turtle population biology in tropical regions are needed and would inform this analysis. This said, differences that may exist but are currently obscured by sampling variation would likely be modest and not likely to change the overall conclusions of this study.

The distinct life history characteristics of turtles at low latitudes (tropical zone) would seem to translate into greater opportunity for sustainable harvest of early stages than those at high latitudes (temperate zone, Fig 5, Table 4). However, our estimated annual sustainable harvest rate $(5 \%)$ of adult turtles is considerably lower than typical thresholds for sustainable harvest rates $(20 \%)$ estimated for long-lived animals $[19,82,83]$. In addition, similar to previous studies [29, 30, 34, 73, 84-87], high adult survival rates are estimated to be critical to maintain population stability due to their relatively greater contribution to population recruitment than other life stages [34]. Considering these results, harvesting wild adults would appear to present a high risk of causing population declines whether in the temperate or tropical regions, reinforcing the need to develop appropriately enforced alternate management options such as farming of captive reared turtles for meat [88].

Although adult harvest is clearly risky $[9,28,87]$ there does appear to be some potential for sustainable exploitation of early stages of tropical freshwater turtle species. Indeed, egg 
392 harvest may be more feasible, because it has low risk of causing population declines (Fig 5).

393 Gibbs and Amato (28) suggest that significant additive mortality in the egg stage may not

394 threaten population persistence and, Thorbjarnarson, Lagueux (8) identified that harvesting of

395 eggs is the most promising strategy in the development of sustainable use programs for turtles.

396 Integrating the conservation and harvest of eggs (for consumption, sale and/or rearing of

397 hatchlings for the pet trade) has generated promising results for the conservation of some

398 threatened tropical turtles e.g. Podocnemis unifilis in Peru [89, 90] and our analysis supports the

399 idea that such actions could be feasible in other tropical turtle species.

We found that tropical populations could continue to grow if egg survival was reduced by

401 up to $35 \%$. We suggest that this surplus of eggs can be applied for both sustainable exploitation

402 and conservation. A focus on management and sustainable exploitation of early life stages (e.g.

403 consumption, pet trade) would also complement conservation actions that generally protect the

404 most sensitive adult stages [9, 28]. We found that the margins for additive mortality are so tight

405 (<10\% in both tropical and temperate species) that the sustainable harvest of adult turtles will

406 likely fail unless additional management actions are incorporated into conservation programs [9].

408 generate more robust and timely increases in exploited turtle populations. Although egg survival

409 produces a relatively small overall effect on population growth rates when compared to adult

410 survival $[28,34]$, demographic simulations show that increasing survival of eggs and hatchlings

411 can compensate for decreases in adult survival in at least one species of tropical turtle [91].

412 Additionally, increasing survival of early stages via community-based protection of turtle nesting

413 beaches has been shown to provide conservation success for local communities [90], target

414 species [90-93] and also non-target vertebrate and invertebrate taxa [92]. Further examples are 
415 needed to understand how the predicted surplus in early life stages can be most effectively

416 exploited so that populations can still increase to replace adults that remain widely targeted and

417 threatened by additional anthropogenic impacts across tropical regions including climate change,

418 forest loss and pollution $[1,9,12,18,19]$.

An important caveat is that the population dynamics of temperate and tropical species in this study were evaluated using the same survival rate values for eggs due to lack of available

421 published data on these parameters both in temperate and tropical species. Mechanisms of

422 protection of egg and juvenile stages do not produce as large an effect on population growth as

423 protecting adult survival [28], so our conclusions are likely to remain valid despite this untested

424 assumption. That said, until data are available on typical nest and juvenile survival in temperate

425 and tropical zones, the relative impact of harvest on populations of temperate and tropical

426 species we estimated must remain tentative.

Together the results of this study imply that sustainable harvesting is difficult to apply as

428 a conservation strategy, both in temperate and tropical turtle species, due to the biological

429 limitations on turtle population growth imposed by their life history strategy everywhere. This

430 said, Eisemberg, Rose (18) suggests that complete prohibition of harvesting as a conservation

431 strategy in turtles will not be possible to implement in tropical areas and developing countries,

432 where local communities have long history in using turtle meat and eggs. Conservation strategies

433 that exclude local communities in their practices are often unsuccessful at protecting wildlife

434 [94]. We reject the assumption often employed in temperate-zone turtle research that "all turtles

435 are the same" yet also note that demographic differences we observed between temperate and

436 tropical turtles do not translate into obviously greater opportunity for sustainable harvest of

437 adults and juveniles in the tropics. Therefore, carefully constructed sustainable harvest programs 
may present greater opportunities to succeed in the tropics if based on egg and hatchling stages, and should be considered further but cautiously for the regions that have a long history of harvesting turtles for subsistence use, particularly when the species possess density dependent mechanisms to compensate harvest, such as shown in $C$. oblonga $[19,42]$.

\section{Acknowledgments}

We thank N. E. Karraker, B. Underwood, and P. R. Sievert for discussions on ideas and their comments on this draft manuscript and to Y-H. Sung for providing life history data for the bigheaded turtle. We thank Jordi Moya-Larano and two anonymous reviewers for their comments on an earlier version of the text.

\section{Author Contributions}

Conceived and designed the experiments: AR, JPG. Performed the experiments: AR, DN, JPG. Analyzed the data: AR, DN, JPG. Contributed reagents/materials/analysis tools: AR, DN, JPG. Wrote the paper: AR, DN, JPG.

\section{Supporting Information}

S1 Table. The life history traits data obtained from literature review.

\section{References}

1. Gibbons JW, Scott DE, Ryan TJ, Buhlmann KA, Tuberville TD, Metts BS, et al. The Global Decline of Reptiles, Deja Vu Amphibians. Bioscience. 2000;50(8):653 - 66. doi: https://doi.org/10.1641/00063568(2000)050[0653:TGDORD]2.0.CO;2.

2. Milner-Gulland EJ, Bennett EL. Wild Meat: The Bigger Picture. TRENDS in Ecology and Evolution. 2003;18(7):351 - 7. doi: https://doi.org/10.1016/S0169-5347(03)00123-X.

3. Santos-Fita D, Naranjo EJ, Rangel-Salazar JL. Wildlife Uses and Hunting Patterns in Rural Communities of the Yucatan Peninsula, Mexico. Journal of Ethnobiology and Ethnomedicine. 2012;8:38.

4. Altrichter M. Wildlife in the Life of Local People of the Semi-Arid Argentine Chaco. Biodiversity and Conservation. 2006;15:2719 - 36. doi: https://doi.org/10.1007/s10531-005-0307-5. 
5. Mena P, Stallings JR, Regalado J, Cueva R. The Sustainability of Current Hunting Practices by the Huaorani. In: Robinson JG, Bennett EL, editors. Hunting for Sustainability in Tropical Forests. New York Columbia University Press; 2000.

6. Townsend WR. The Sustainability of Subsistence Hunting by the Siriono Indians of Bolivia. In: Robinson JG, Bennett EL, editors. Hunting for Sustainabillity in Tropical Forests. New York: Columbia University Press; 2000.

7. Moll D, Moll EO. The Ecology, Exploitation, and Conservation of River Turtles. New York: Oxford University Press; 2004.

8. Thorbjarnarson J, Lagueux CJ, Bolze D, Klemens MW, Meylan AB. Human Use of Turtles: A Wordwide Perspective. In: Klemens MW, editor. Turtle Conservation. Washington, DC: The Smithsonian Institution; 2000.

9. Spencer RJ, Dyke JU, Thompson MB. Critically evaluating best management practices for preventing freshwater turtle extinctions. Conservation Biology. 2017;31(6):1340-9. doi: https://doi.org/10.1111/cobi.12930.

10. Congdon JD, Greene JL, Gibbons JW. Biomass of Freshwater Turtles: A Geographic Comparison. American Midland Naturalist. 1986;115(1):165 - 73. doi: https://doi.org/10.2307/2425846.

11. Iverson JB. Biomass in Turtle Populations: A Neglected Subject. Oecologia. 1982;55(1):69 - 76. doi: https://doi.org/10.1007/BF00386720.

12. He F, Bremerich V, Zarfl C, Geldmann J, Langhans SD, David JN, et al. Freshwater megafauna diversity: Patterns, status and threats. Diversity and Distributions. 2018;24(10):1395-404. doi: https://doi.org/10.1111/ddi.12780.

13. Lovich JE, Ennen JR, Agha M, Gibbons JW. Where have all the turtles gone, and why does it matter? Bioscience. 2018;68(10):771-81. doi: https://doi.org/10.1093/biosci/biy095.

14. Saha A, McRae L, Dodd Jr CK, Gadsden H, Hare KM, Lukoschek V, et al. Tracking global population trends: Population time-series data and a living planet index for reptiles. Journal of Herpetology. 2018;52(3):259-68. doi: https://doi.org/10.1670/17-076.

15. Rhodin AG, Stanford CB, Van Dijk PP, Eisemberg C, Luiselli L, Mittermeier RA, et al. Global conservation status of turtles and tortoises (Order Testudines). Chelonian Conservation and Biology. 2018;17(2):135-61. doi: https://doi.org/10.2744/CCB-1348.1.

16. Klemens MW, Thorbjarnarson JB. Reptiles as a Food Resource. Biodiversity and Conservation. 1995;4:281 - 98. doi: https://doi.org/10.1007/BF00055974.

17. Moll EO, Moll D. Conservation of River Turtles. In: Klemens MW, editor. Turlte Conservation. Washington, DC: The Smithsonian Institution; 2000.

18. Eisemberg CC, Rose M, Yaru B, Georges A. Demonstrating Decline of an Iconic Species Under Sustained Indigenous Harvest - The Pig - Nosed Turtle (Carettochelys insculpta) in Papua New Guinea. Biological Conservation. 2011;144:2282 - 8. doi: https://doi.org/10.1016/j.biocon.2011.06.005.

19. Fordham DA, Georges A, Brook BW. Indigeneous Harvest, Exotic Pig Predation and Local Persistence of a Long - Lived Vertebrate: Managing a Tropical Freshwater Turtle for Sustainability and Conservation. Journal of Applied Ecology. 2008;45:52 - 62. doi: https://doi.org/10.1111/j.13652664.2007.01414.x.

20. Gamble T, Simons AM. Comparison of Harvested and Nonharvested Painted Turtle Populations. Wildlife Society Bulletin. 2004;32(4):1269 - 77. doi: https://doi.org/10.2193/00917648(2004)032[1269:COHANP]2.0.CO;2.

21. Sung $\mathrm{YH}$, Karraker NE, Hau BCH. Demographic Evidence of Illegal Harvesting of an Endangered Asian Turtle. Conservation Biology. 2013;27(6):1421 - 8. doi: https://doi.org/10.1111/cobi.12102.

22. Iverson JB. Golbal Correlates of Species Richness in Turtles. The Herpetological Journal. 1992;2(3):77 - 81. 
23. Mittermeier RA. South America's River Turtles: Saving Them by Use Oryx. 1978;14:222 - 30. doi: https://doi.org/10.1017/S0030605300015532.

24. Mali I, Vandewege MW, Davis SK, Forstner MRJ. Magnitude of the Freshwater Turtle Exports from the US: Long Term Trends and Early Effects of Newly Implemented Harvest Management Regimes. PLOS ONE. 2014;9(1):e86478. doi: https://doi.org/10.1371/journal.pone.0086478.

25. McNeely JA, Miller KR, Reid WV, Mittermeier RA, Werner TB. Conserving the World's Biological Diversity. Washington, D. C.: IUCN, Gland, Switzerland, WRI, Cl, WWF - US, and the World Bank; 1990.

26. Webb GJ. Conservation and Sustainable Use of Wildlife - An Evolving Concept. Pacific Conservation Biology. 2002;8:12 - 26.

27. Fitzgerald LA. Tupinambis Lizards and People: A Sustainable Use Approach to Conservation Development. Conservation Biology. 1994;8(1):12 - 5.

28. Gibbs JP, Amato GD. Genetics and Demography in Turtle Conservation. In: Klemens MW, editor. Turtle Conservation. Washington, DC: The Smithsonian Institution; 2000.

29. Congdon JD, Dunham AE, van Loben Sels RC. Delayed Sexual Maturity and Demographics of Blanding's Turtles (Emydoidea blandingii): Implications for Conservation and Management of Long Lived Organisms. Conservation Biology. 1993;7(4):826 - 33. doi: https://doi.org/10.1046/i.15231739.1993.740826.x.

30. Congdon JD, Dunham AE, van Loben Sels RC. Demographics of Common Snapping Turtles (Chelydra serpentina): Implications for Conservation and Management of Long - Lived Organisms. American Zoologist. 1994;34(3):397 - 408. doi: https://doi.org/10.1093/icb/34.3.397.

31. Doroff AM, Keith LB. Demography and Ecology of an Ornate Box Turtle (Terrapene ornata) Population in South-Central Wisconsin. Copeia. 1990;1990(2):387 - 99 . doi: https://doi.org/10.2307/1446344

32. Iverson JB. Patterns of survivorship in turtles (order Testudines). Canadian Journal of Zoology. 1991;69:385 - 91. doi: https://doi.org/10.1139/z91-060.

33. Iverson JB. Correlates of Reproductive Output in Turtles (Order Testudines). Herpetological Monographs. 1992;6:25 - 42. doi: https://doi.org/10.2307/1466960

34. Heppell SS. Application of Life - History Theory and Population Model Analysis to Turtle Conservation. Copeia. 1998;1998(2):367 - 75. doi: https://doi.org/10.2307/1447430.

35. Burke VJ, Gibbons JW, Greene JL. Prolonged Nesting Forays by Common Mud Turtles (Kinosternon subrurbrum). American Midland Naturalist. 1994;131(190 - 195). doi: https://doi.org/10.2307/2426622.

36. Iverson JB, Higgins $H$, Sirulink A, Griffiths C. Local and Geographic Variation in the Reproductive Biology of the Snapping Turtle (Chelydra serpentina). Herpetologica. 1997;53(1):96 - 117.

37. Shine R, Iverson JB. Patterns of survival, growth and maturation in turtles. OIKOS. 1995;72:343 8. doi: https://doi.org/10.2307/3546119.

38. Angielczyk KD, Burroughs RW, Feldman CR. Do turtles follow the rules? Latitudinal gradients in species richness, body size, and geographic range area of the world's turtles. Journal of Experimental Zoology Part B: Molecular and Developmental Evolution. 2015;324(3):270-94. doi: https://doi.org/10.1002/jez.b.22602.

39. Santilli J, Rollinson N. Toward a general explanation for latitudinal clines in body size among chelonians. Biological Journal of the Linnean Society. 2018;124(3):381-93. doi: https://doi.org/10.1093/biolinnean/bly054.

40. Storey KB, Storey JM. Molecular physiology of freeze tolerance in vertebrates. Physiological Reviews. 2017;97(2):623-65. doi: https://doi.org/10.1152/physrev.00016.2016.

41. Iverson JB, Balgooyen CP, Byrd KK, Lyddan KK. Latitudinal Variation in Egg and Cutch Size in Turtles. Canadian Journal of Zoology. 1993;71:2448 - 61. doi: https://doi.org/10.1139/z93-341. 
42. Fordham DA, Georges A, Brook BW. Demographic Response of Snake - Necked Turtles Correlates with Indigenous Harvest and Feral Pig Predation in Tropical Northern Australia. Journal of Animal Ecology. 2007;76:1231 - 43. doi: https://doi.org/10.1111/i.1365-2656.2007.01298.x.

43. Salguero-Gómez R, Jones OR, Archer CR, Bein C, de Buhr H, Farack C, et al. COMADRE: a global data base of animal demography. Journal of Animal Ecology. 2016;85(2):371-84. doi: https://doi.org/10.1111/1365-2656.12482.

44. Fick SE, Hijmans RJ. WorldClim 2: new 1-km spatial resolution climate surfaces for global land areas. International Journal of Climatology. 2017;37(12):4302-15. doi: https://doi.org/10.1002/joc.5086. 45. Sunday JM, Bates AE, Dulvy NK. Global analysis of thermal tolerance and latitude in ectotherms. Proceedings of the Royal Society B: Biological Sciences. 2010;278(1713):1823-30. doi: https://doi.org/10.1098/rspb.2010.1295.

46. Wood SN. Fast stable restricted maximum likelihood and marginal likelihood estimation of semiparametric generalized linear models. Journal of the Royal Statistical Society: Series B (Statistical Methodology). 2011;73(1):3-36. doi: https://doi.org/10.1111/i.1467-9868.2010.00749.x.

47. Wood SN. Generalized additive models: an introduction with R: Chapman and Hall/CRC; 2017.

48. Wood SN. A simple test for random effects in regression models. Biometrika. 2013;100(4):100510. doi: https://doi.org/10.1093/biomet/ast038.

49. Pedersen EJ, Miller DL, Simpson GL, Ross N. Hierarchical generalized additive models in ecology: an introduction with mgcv. PeerJ. 2019;7:e6876. doi: https://doi.org/10.7717/peeri.6876.

50. Rhodin A, Iverson J, Bour R, Fritz U, Georges A, Shaffer H, et al. Turtles of the world: annotated checklist and atlas of taxonomy, synonymy, distribution, and conservation status. Conservation biology of freshwater turtles and tortoises: a compilation project of the IUCN/SSC Tortoise and Freshwater Turtle Specialist Group Chelonian Research Monographs. 2017;7:1-292. doi: 10.3854/crm.7.checklist.atlas.v8.2017.

51. R Development Core Team. R: A language and environment for statistical computing. Vienna, Austria: R Foundation for Statistical Computing; 2019.

52. Burnham KP, Anderson DR. Model Selection and Multi-Model Inference: A Practical InformationTheoretic Approach. 2 ed. New York: Springer; 2002. 496 p.

53. Zuur AF, leno EN, Smith GM. Analysing Ecological Data. Gail M, Krickeberg K, Samet JM, Tsiatis A, Wong W, editors. New York: Springer; 2007.

54. Caswell H. Matrix population models: construction, analysis, and interpretation: Sinauer Associates; 1989.

55. Lefkovitch L. The study of population growth in organisms grouped by stages. Biometrics. 1965:1-18.

56. Crouse DT, Crowder LB, Caswell H. A Stage - Based Population Model fro Loggerhead Sea Turtles and Implications for Conservation. Ecology. 1987;68(5):1412 - 23. doi: https://doi.org/10.2307/1939225. 57. Stott I, Hodgson D, Townley S. popdemo: Demographic Modelling Using Projection Matrices. R package version 0.2-3 ed2016.

58. Stubben C, Milligan B. Estimating and analyzing demographic models using the popbio package in R. Journal of Statistical Software. 2007;22(11):1-23.

59. Pike DA, Pizzato L, Pike BA, Shine R. Estimating Survival Rates of Uncatchable Animals: The Myth of High Juvenile Mortality in Reptiles. Ecology. 2008;89(3):607 - 11. doi: https://doi.org/10.1890/062162.1.

60. Manly BF. Randomization, bootstrap and Monte Carlo methods in biology: Chapman and Hall/CRC; 2018.

61. Benton TG, Plaistow SJ, Coulson TN. Complex Population Dynamics and Complex Causation: Devils, Details and Demography. Proceedings of The Royal Society B. 2006;273:1173 - 81. doi: https://doi.org/10.1098/rspb.2006.3495. 
605

606

607

608

609

610

611

612

613

614

615

616

617

618

619

620

621

622

623

624

625

626

627

628

629

630

631

632

633

634

635

636

637

638

639

640

641

642

643

644

645

646

647

648

649

650

651

652

62. Stearns SC. The Evolution of Life Histories. New York: Oxford University Press; 1992.

63. Stearns SC. The evolution of life history traits: a critique of the theory and a review of the data. Annual Review of Ecology and Systematics. 1977;8(1):145-71. doi: https://doi.org/10.1146/annurev.es.08.110177.001045.

64. Congdon JD, Gibbons JW. The Evolution of Turtle Life Histories. In: Gibbons JW, editor. Life History and Ecology of the Slider Turtle. Washington, D. C.: Smithsonian Institution Press; 1990.

65. Jonsson B, Jonsson N, Brodtkorb E, Ingebrigtsen PJ. Life-history traits of brown trout vary with the size of small streams. Functional Ecology. 2001;15(3):310-7. doi: https://doi.org/10.1046/i.13652435.2001.00528.x.

66. Macip-Ríos R, Ontiveros RN, Sánchez-León AT, Casas-Andreu G. Evolution of reproductive effort in mud turtles (Kinosternidae): the role of environmental predictability. Evolutionary Ecology Research. 2017;18(5):539-54.

67. Tokolyi J, Schmidt J, Barta Z. Climate and Mammalian Life Histories. Biological Journal of the Linnean Society. 2014;111(719 - 736). doi: https://doi.org/10.1111/bij.12238.

68. McNamara JM, Barta Z, Wikelski M, Houston Al. A Theoritical Investigation of the Effect of Latitude on Avian Life Histories. The American Naturalist. 2008;172(3):331 - 45. doi: https://doi.org/10.1086/589886.

69. Hutchings JA, Myers RA, García VB, Lucifora LO, Kuparinen A. Life-history correlates of extinction risk and recovery potential. Ecological Applications. 2012;22(4):1061-7. doi: https://doi.org/10.1890/111313.1.

70. Martin TE, Martin PR, Olson CR, Heidinger BJ, Fontaine JJ. Parental Care and Clutch Sizes in North and South American Birds. Science. 2000;287:1482 - 5 . doi: https://doi.org/10.1126/science.287.5457.1482

71. Obbard ME, Brooks RJ. Nesting Migrations of the Common Snapping Turtle Chelyydra serpentina. Herpetologica. 1980;36:158 - 62.

72. Galbraith DA, Brooks RJ, Obbard ME. The Influence of Growth Rate on Age and Body Size at Maturity in Female Snapping Turtles (Chelydra serpentina) Copeia. 1989;1989(4):896 - 904. doi: https://doi.org/10.2307/1445975.

73. Spencer RJ. Growth Patterns of Two Widely Distributed Freshwater Turtles and a Comparison of Common Methods Used to Estimate Age. Australian Journal of Zoology. 2002;50:477 - 90. doi: https://doi.org/10.1071/ZO01066.

74. Tinkle DW. Geographic Variation in Reproduction, Size, Sex Ratio and Maturity of Sternotherus odoratus (Testudinata: Chelydridae). Ecology. 1961;42:68 - 76. doi: https://doi.org/10.2307/1933268

75. Dunham AE, Gibbons JW. Growth of the Slider Turtle. In: Gibbons JW, editor. Life History and Ecology of the Slider Turtle. Washington, D. C.: Smithsonian Institution Press; 1990. p. 135 - 45.

76. Gibbons JW, Semlitsch RD, Greene JL, Schibauer JP. Variation in Age and Size at Maturity of the Slider Turtle (Pseudemys scripta). The American Naturalist. 1981;117(5):841 - 5 . doi: https://doi.org/10.1086/283774.

77. Ashton KG, Feldman CR. Bergmann's rule in nonavian reptiles: turtles follow it, lizards and snakes reverse it. Evolution. 2003;57(5):1151-63. doi: https://doi.org/10.1111/j.00143820.2003.tb00324.x.

78. Gilbert SF, Cebra - Thomas JA, Burke AC. How the Turtle Gets Its Shell. In: Wyneken J, Godfrey $\mathrm{MH}$, Bels V, editors. Biology of Turtles: From Structures to Strategies of Life. USA: CRC Press, Taylor \& Francis Group; 2008.

79. Zug GR, Vitt L, Caldwell JP. Herpetology: An Introductory Biology of Amphibians and Reptiles. 2nd ed. San Diego, California, USA: Academic Press; 2001.

80. Jackson DC. How a Turtle's Shell Helps It Survive Prolonged Anoxic Acidosis. News Physiological Science. 2000;15:181 - 5. doi: https://doi.org/10.1152/physiologyonline.2000.15.4.181. 
81. Crawley MJ. The R Book. UK: John Wiley \& Sons, Ltd.; 2007.

82. Robinson JG, Bennett EL. Carrying Capacity Limits to Sustainable Hunting in Tropical Forests. In: Robinson JG, Bennett EL, editors. Hunting for Sustainability in Tropical Forests. New York: Columbia University Press; 1990.

83. Robinson JG, Bodmer RE. Towards Wildlife Management in Tropical Forests. The Journal of Wildlife Management. 1999;63(1):1 - 13. doi: https://doi.org/10.2307/3802482.

84. Blamires SJ, Spencer RJ, King P, Thompson MB. Population Parameters and Life - Table Analysis of Two Coexisting Freshwater Turtles: Are the Bellinger River Turtle Populations Threatened? Wildlife Research. 2005;32(4):339 - 47. doi: https://doi.org/10.1071/WR04083.

85. Macip-Rios R, Brauer-Robleda P, Zuniga-Vega JJ, Casas-Andreu G. Demography of two populations of the Mexican mud turtle (Kinosternon integrum) in central Mexico. Herpetological Journal. 2011;21:235 - 45 .

86. Spencer RJ, Thompson MB. Experimental Analysis of the Impact of Foxes on Freshwater Turtle Populations. Conservation Biology. 2005;19(3):845 - 54. doi: https://doi.org/10.1111/i.15231739.2005.00487.x.

87. Zimmer-Shaffer SA, Briggler JT, Millspaugh JJ. Modeling the effects of commercial harvest on population growth of river turtles. Chelonian Conservation and Biology. 2014;13(2):227-36. doi: https://doi.org/10.2744/CCB-1109.1.

88. Mali I, Wang H-H, Grant WE, Feldman M, Forstner MRJ. Modeling Commercial Freshwater Turtle Production on US Farms for Pet and Meat Markets. PLOS ONE. 2015;10(9):e0139053. doi: https://doi.org/10.1371/journal.pone.0139053.

89. Sinovas P, Price B, King E, Hinsley A, Pavitt A. Wildlife trade in the Amazon countries: an analysis of trade in CITES listed species. Cambridge, UK: Technical report prepared for the Amazon Regional Program, 2017.

90. Harju E, Sirén AH, Salo M. Experiences from harvest-driven conservation: Management of Amazonian river turtles as a common-pool resource. Ambio. 2017;47:327. doi: https://doi.org/10.1007/s13280-017-0943-5.

91. Norris D, Peres CA, Michalski F, Gibbs JP. Prospects for freshwater turtle population recovery are catalyzed by pan-Amazonian community-based management. Biological Conservation. 2019;233:51-60. doi: https://doi.org/10.1016/i.biocon.2019.02.022.

92. Campos-Silva JV, Hawes JE, Andrade PC, Peres CA. Unintended multispecies co-benefits of an Amazonian community-based conservation programme. Nature Sustainability. 2018;1(11):650. doi: https://doi.org/10.1038/s41893-018-0170-5.

93. Norris D, Michalski F, Gibbs JP. Community involvement works where enforcement fails: conservation success through community-based management of Amazon river turtle nests. PeerJ. 2018;6:e4856. doi: https://doi.org/10.7717/peerj.4856.

94. Pimhert MP, Pretty JN. Diversity and Sustainability in Community Based Conservation. In: Kothari A, Pathak N, Anuradha RV, Taneja B, editors. Communities and Conservation: Natural Resource Management in South and Central Asia. Sage Publication: New Delhi, India; 1998. p. 58 - 77. 


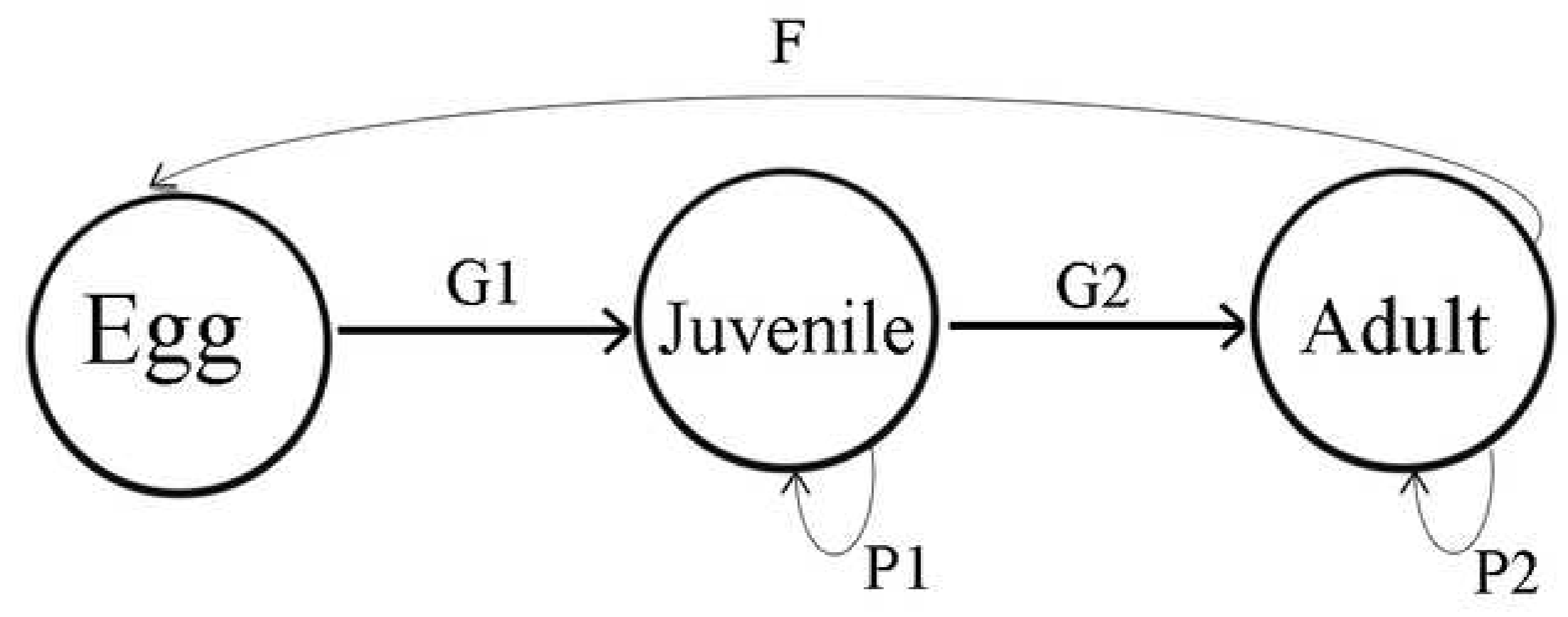




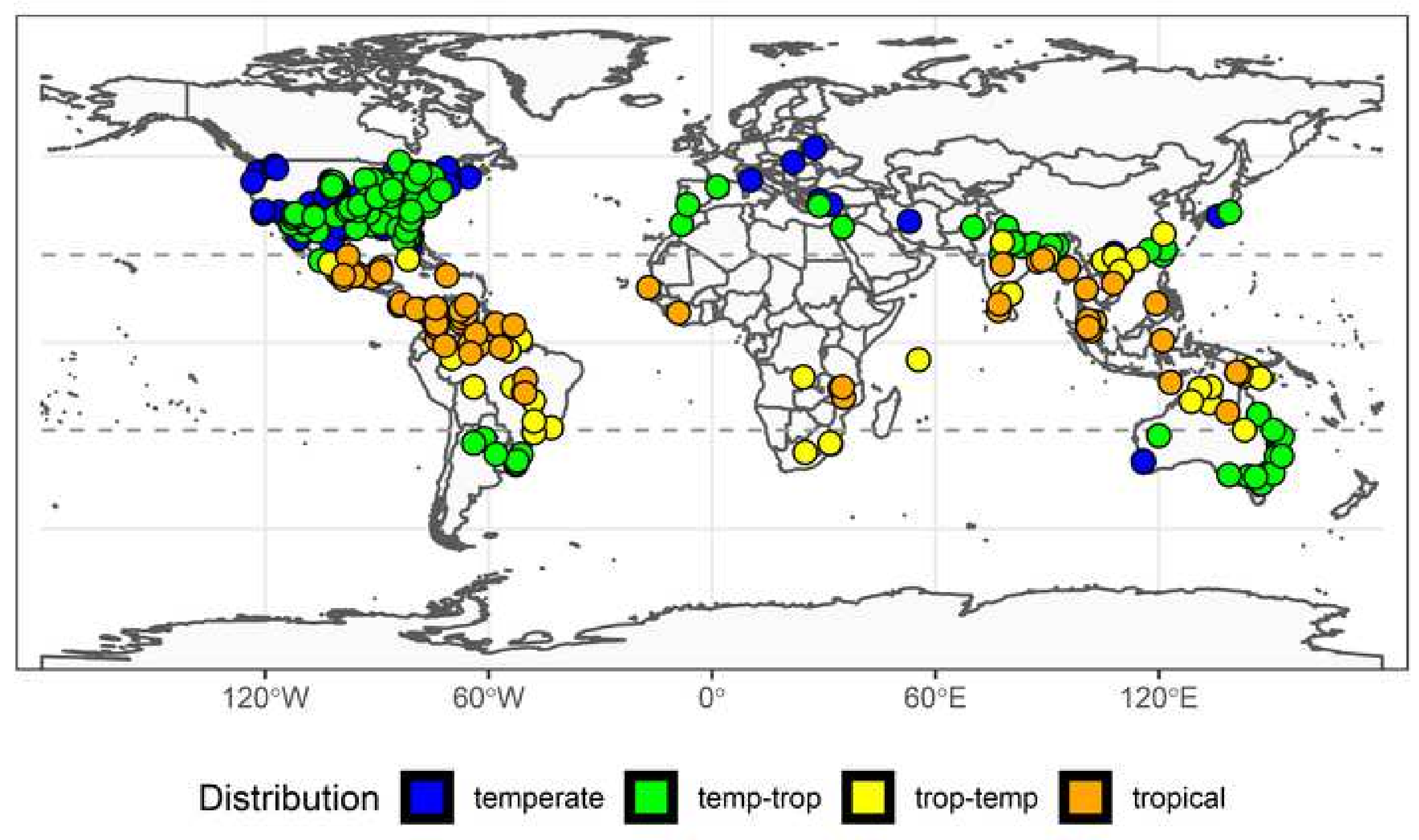


(A)
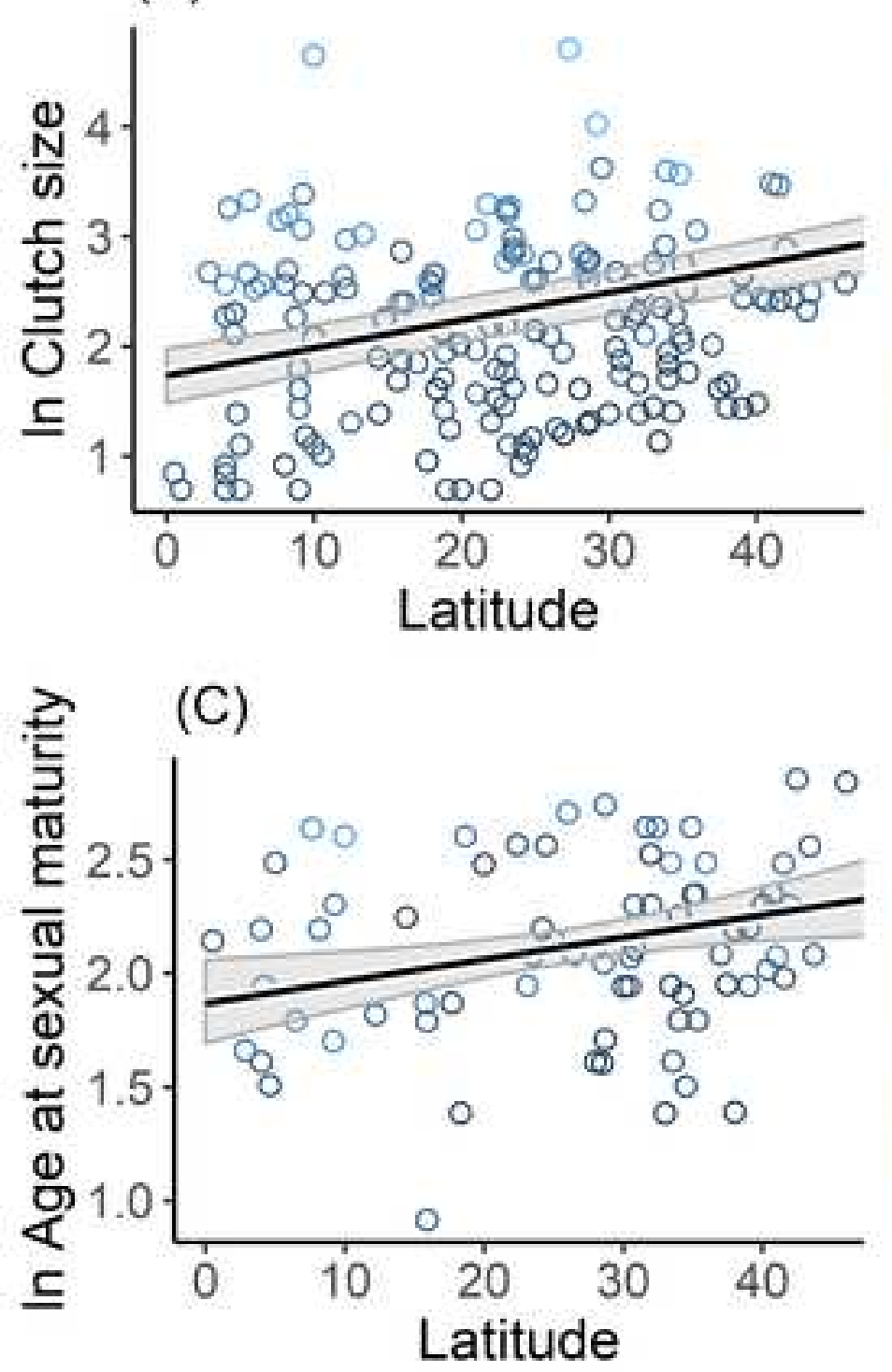

(B)
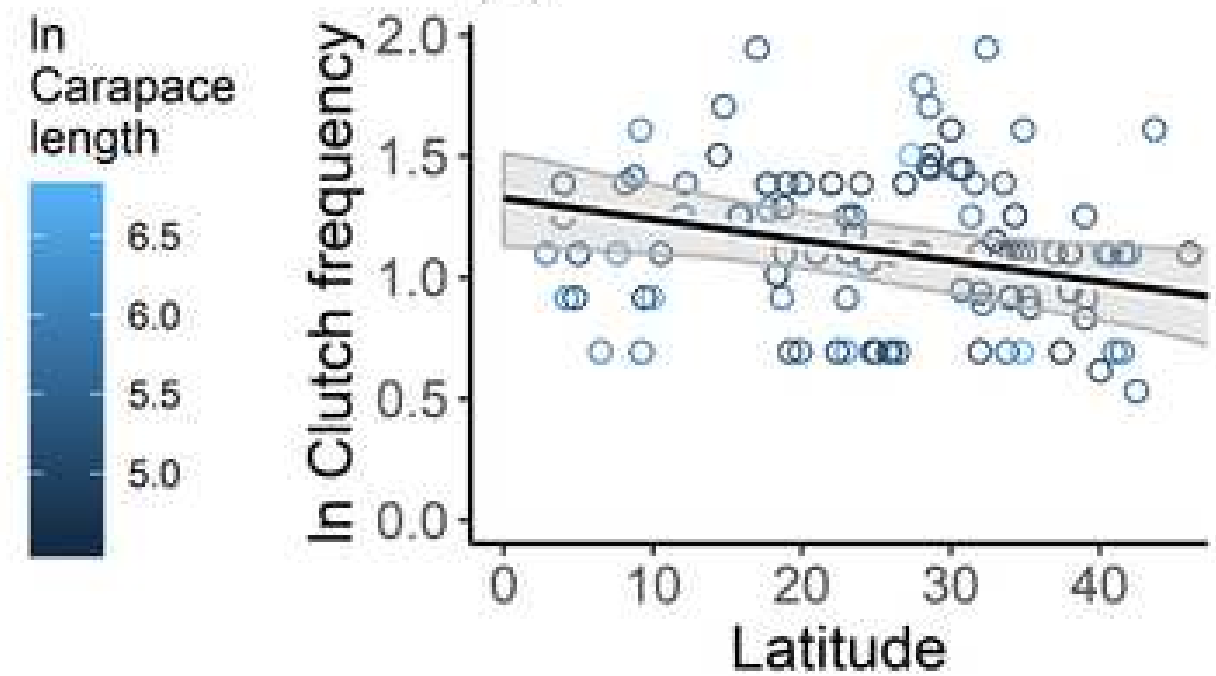

In

Carapace length

6.5

6.0

5.5

5.0

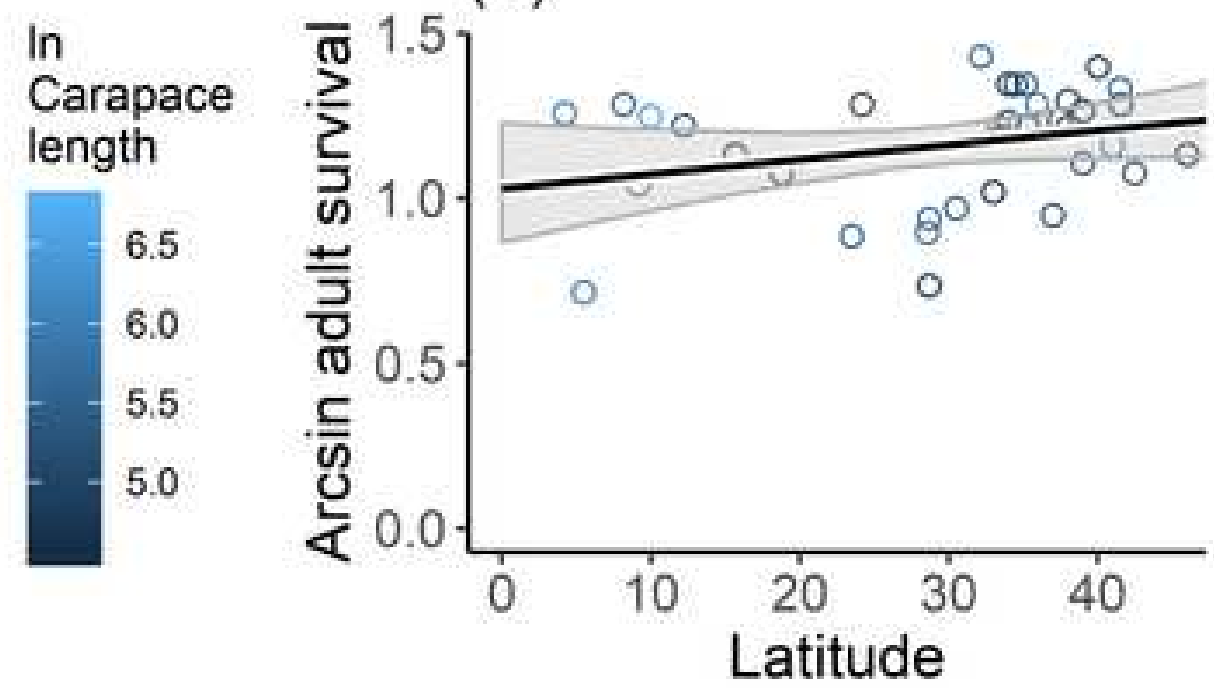

In Carapace length

6.5

6.0

5.5

5.0 
(A)

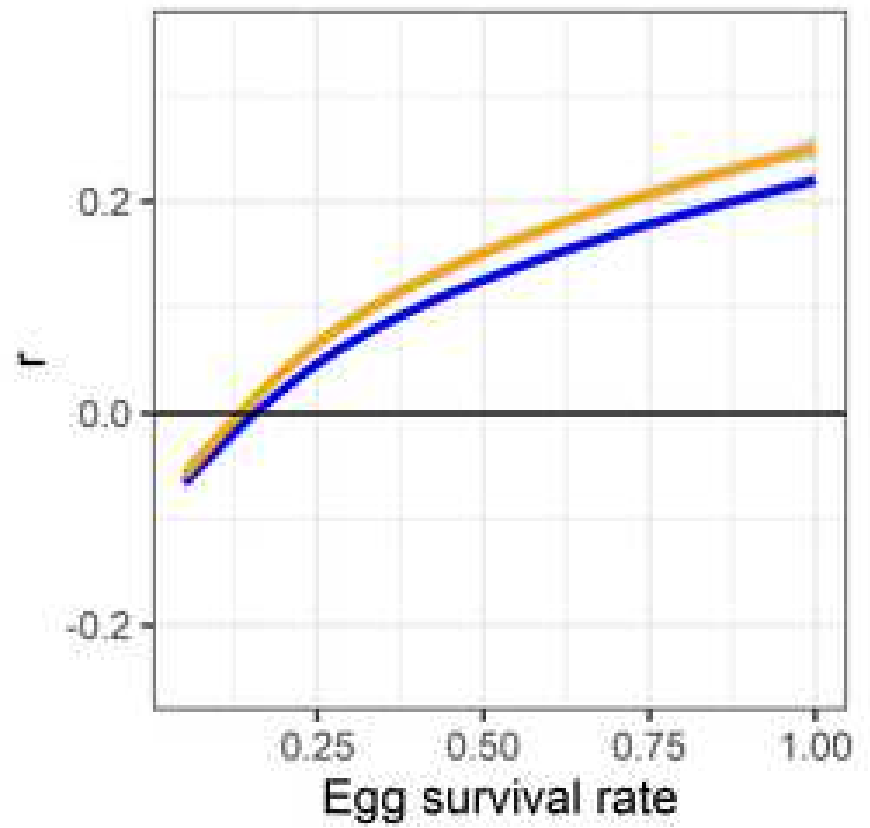

(C)

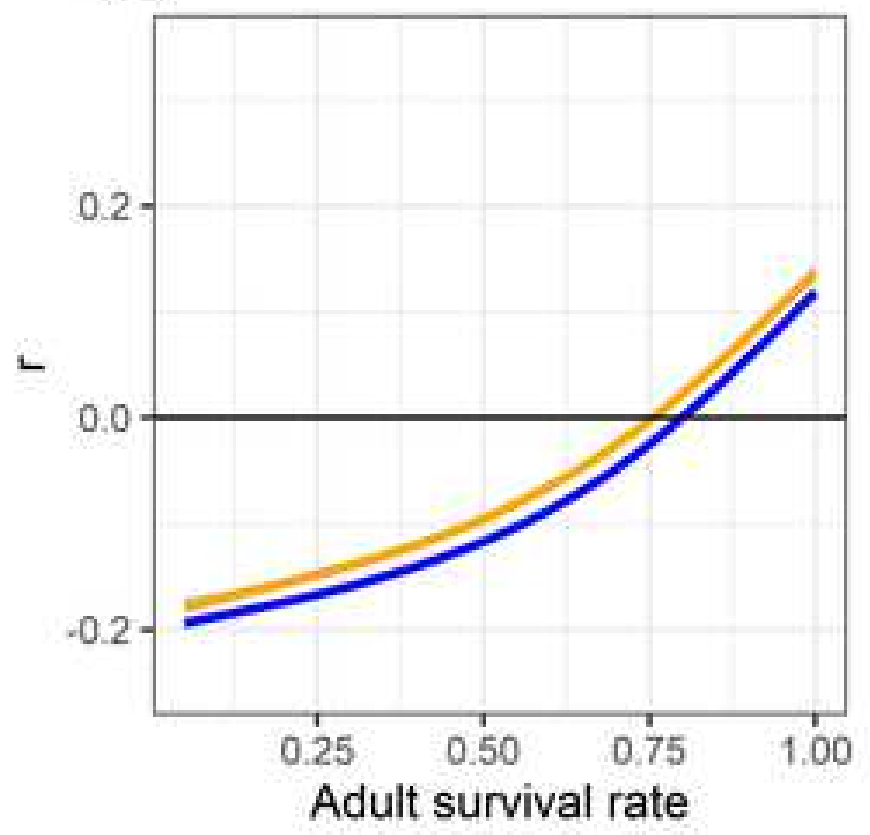

(B)
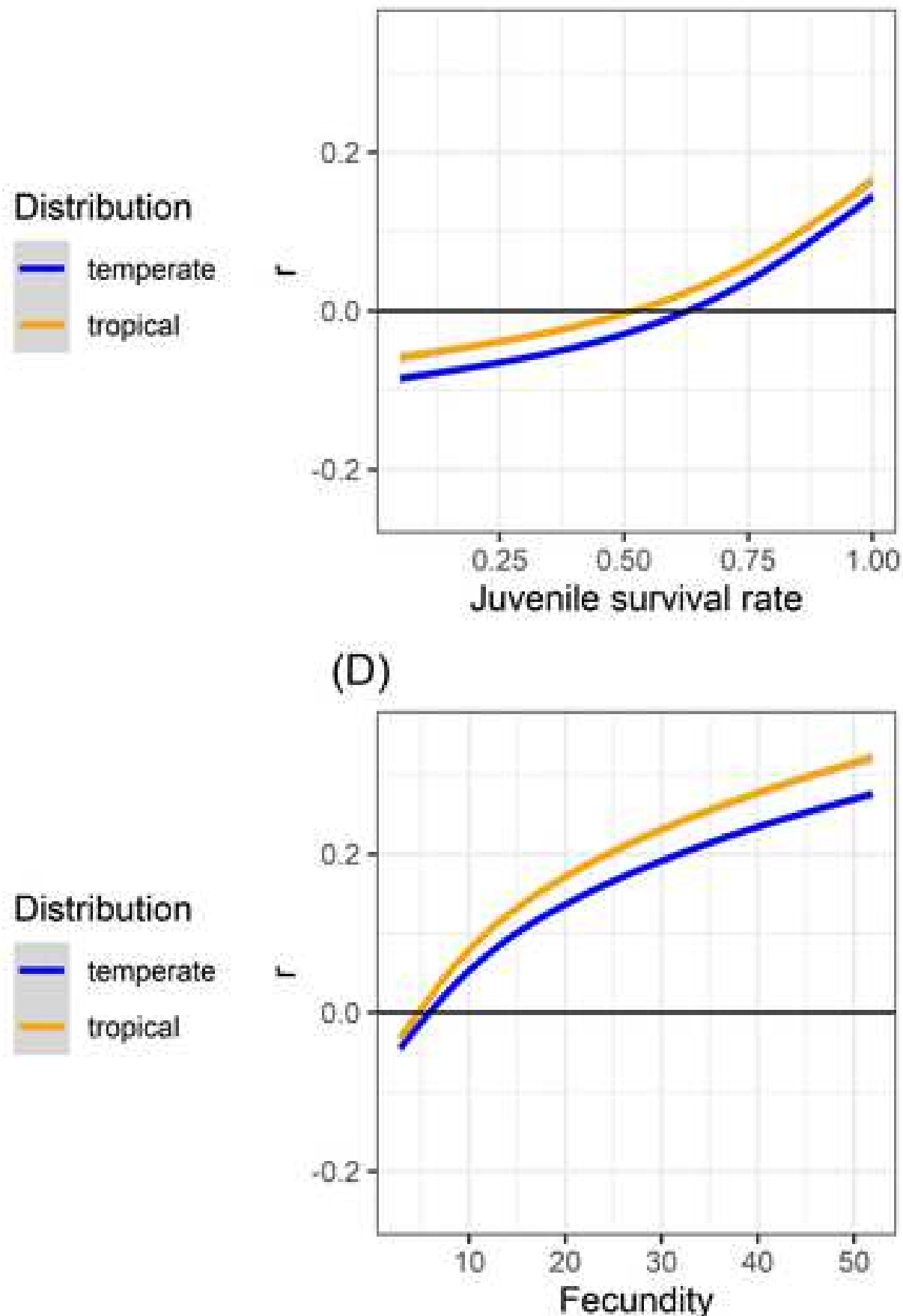

ᄂ

(D)

\section{Distribution}

- temperate

tropical

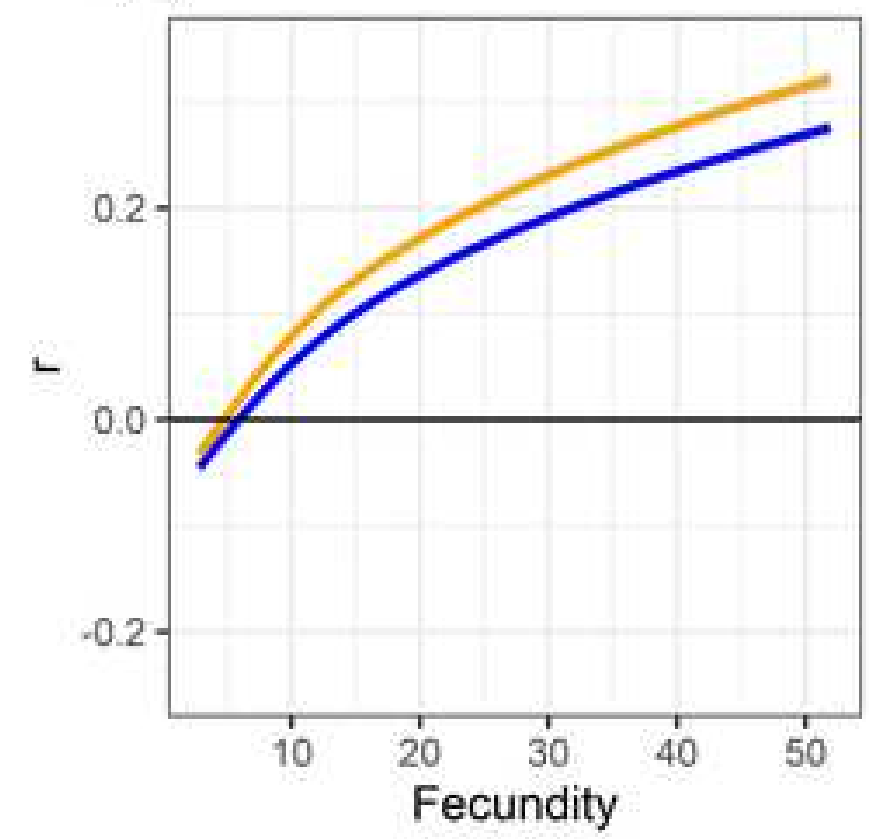

Distribution

temperate

tropical 
Click here to access/download

\section{Supporting Information S1_Table.docx}


From: PLOS ONE <em@editorialmanager.com>

Date: Sat, Dec 5, 2015 at 5:08 PM

Subject: PLOS ONE Decision: Revise [PONE-D-15-44735] - [EMID:be9d1b1768505f52]

To: angga rachmansah <angga.rachmansah@gmail.com>

PONE-D-15-44735

Biological Feasibility of Sustainable Harvesting Programs as a Conservation Strategy for Tropical Freshwater Turtles

PLOS ONE

Dear Mr rachmansah,

Thank you for submitting your manuscript to PLOS ONE. After careful consideration, we feel that it has merit, but is not suitable for publication as it currently stands. Therefore, my decision is "Major Revision."

We invite you to submit a revised version of the manuscript that addresses the points below:

*** I liked this ms very much and think that after you address the comments of the referees and those of my own it should be ready for publication. However, I must warn you that these changes may be substantial.

Both reviews are excellent and hope that you can make a good use of them. Rev. \#1 provides relevant comments to improve your ms and especially points to missing literature that should be cited and Rev. \#2 suggests expanding and changing the statistical analyses and has main concerns on the modelling which should be addressed before publication is granted. This reviewer suggests to look at explanatory patterns within each latitude (basically what it could be summarized as looking for a predictor*latitude interaction on life history traits). He/she also asks for you to state your predictions/expectations beforehand in your Intro and Methods section.

I found that the Discussion is the weakest part of the ms, particularly because you mostly address the turtle literature but do not frame it in the extensive literature on life history traits. I provide some hints to help improving the Discussion and finding support to your findings from what we know across organisms and from theoretical standpoints.

Unfortunately your ms did not have line nor page numbers. In order to comment on it I therefore copied the actual text that I am referring to without reference to any page or line numbers.

What is " $A$ " in the model?

Our reply: We have clarified the text (p l) as follows "The discrete stage based lifecycle (Fig 1) can be presented as a population projection matrix " $A$ " as follows:"

A sensitivity analysis changing the 0.2 egg survival rate value would be advisable, as we know that usually interactions are stronger in the tropics (literature by Dobzhansky, Schemske, summarized in Bekmam 2013 Ecol. Lett. 16:1054-1060) and this value could actually change with latitude. The same could apply to other sources of (adult and juvenile) mortality, as in principle predation and parasitism (sources of mortality) should be higher in the tropics.

Our reply: We include results from the sensitivity analysis in Figure 5. We have now included estimate of variation around this 0.2 value in our sensitivity analysis (standard deviation from Iverson 1991). The egg survival value is likely to vary but the most robust synthesis available 
suggest that 0.2 is a suitable value for freshwater species (Iverson 1991). Our estimates of juvenile mortality are expressed as a percentage of adult mortality. These values and their range (from species level data) are included in the sensitivity analysis. There are therefore differences in juvenile survival values between temperate and tropical zone species (see updated Table 4 and Figure 5). We have updated and clarified the Methods to reflect this. We are not aware of any studies that present empirical data necessary to robustly inform a more in-depth analysis. We hope that future studies can further refine these analyses.

Gibbs JP, Amato GD. Genetics and Demography in Turtle Conservation. In: Klemens MW, editor. Turtle Conservation. Washington, DC: The Smithsonian Institution; 2000.

Iverson JB. Patterns of survivorship in turtles (order Testudines). Canadian Journal of Zoology. 1991;69:385 - 91.

In particular, the above could also respond to this paragraph: "An important caveat is that the population dynamics of temperate and tropical species in this study were evaluated using the same survival rate values for egg and juvenile stages due to lack of available published data on these parameters both in temperate and tropical species. Mechanisms of protection of egg and juvenile stages do not produce as large an effect on population growth as to protections adult survival [24], so our conclusions may remain valid despite this unassessed assumption. That said, until data are available on typical nest and juvenile survival in temperate and tropical zones, the relative impact of harvest on populations of temperate and tropical species we estimated must remain tentative." Our reply: We share data and code to encourage further studies to address the broad range of questions that can be asked with the data we have compiled and shared. We believe that until data are available on typical nest and juvenile survival in temperate and tropical zones, the relative impact of harvest on populations of temperate and tropical species we estimated must remain tentative.

The reported values do not match the text, please check: "whereas natural logarithm of clutch frequency $(\beta=-0.04 ; \mathrm{P}<0.001)$ was positively related to annual mean temperature (Fig 4)." Our reply: Based on the helpful suggestions from both the editor and reviewers we have extensively updated the analysis and results. The text has been revised to ensure consistency of the reported values.

"confidence intervals" in regression fits (where the spread of the confidence region changes with X) should be "confidence bands". Please, change accordingly.

Our reply: We have updated the text accordingly.

Discussion

Please provide R2 values of your lmer models (see Nakagawa 2013 Meth Ecol Evol and library MuMIn in R) to support this sentence in the Discussion: "The results of this study revealed that turtle life history is strongly related to latitude and ambient temperature."

Our reply: Based on the helpful suggestions from the editor and reviewers we have extensively updated the analysis and results. We have included $r 2$ values in the revised version (Table 3).

A low p-value or a regression coefficient without standardization is not enough to support your claims. A large proportion of the variance may be still left to be explained.

Our reply: Based on the helpful suggestions from the editor and reviewers we have extensively 
updated the analysis and results. We have also revised the text to ensure conclusions and results are supported by the data and analysis presented.

"Iverson et al. [32] concluded that higher juvenile competition due to shorter time period for development along with higher egg mortality associated with winter and climate uncertainty that creates temporary periods of low competition may make it more advantageous for temperate turtle species to produce more offspring as a "bet hedging" strategy to exploit temporary resources." This is too speculative, especially since you use a 0.2 egg survival rate from one single place because there are not comparative data available. Is there evidence that buried eggs suffer mortality from cold temperatures?

Our reply: We have now added the reference of Iverson 1991 [1] to the sentence. This is one of the classic turtle demography references, including a pioneering and meticulous compilation of 81 age-class-specific survivorship values representing 30 turtle species. It is not a "single place". Iverson [1] provides a combined early stage (egg - to 1 year) annual survival estimate of $0.215+0.188$ for freshwater turtles (includes eggs, hatchlings, 1 year that were combined due to "lack of significant differences in survivorship across these three age-classes"). Egg mortality is affected by myriad factors (see supporting references below). But for freshwater turtle species survival estimates of all these early stages are firmly anchored around 0.2 and the SD value (see above) also suggests a consistently low survival value for early stages. In addition for long lived species with multiple reproductive events and in the case of turtles multiple egg laying events, egg survival has consistently been demonstrated to be far less important than survival in juvenile and adult stages $[2,3]$. Buried eggs can suffer mortality from extreme temperatures (too hot and too cold) and desiccation in both temperate and tropical zones. Turtles have a number of behavioral (e.g. nest depth, substrate choice) and physiological (egg shell thickness, size and shape) adaptations that can help reduce egg mortality (see examples in supporting references below). Such factors are species and location specific. However, we feel that such factors do not affect our conclusions and are not highly relevant to our Discussion. For example, our main finding is that adult harvest is extremely risky (likely to be unsustainable) in both tropical and temperate turtle species. This conclusion is based on an unprecedented compilation of species level demographic data and robust modeling of population dynamics (including sensitivity analysis). For all these reasons we prefer to retain the use of 0.2 egg survival and hope future studies can further refine these analyses based on the data and code we share.

[1] Iverson JB. Patterns of survivorship in turtles (order Testudines). Canadian Journal of Zoology. 1991 Feb 1;69(2):385-91.

[2]Gibbs JP, Amato GD. Genetics and Demography in Turtle Conservation. In: Klemens MW, editor. Turtle Conservation. Washington, DC: The Smithsonian Institution; 2000.

[3] Heppell SS. Application of Life - History Theory and Population Model Analysis to Turtle Conservation. Copeia. 1998;1998(2):367 - 75.

Supporting references relevant for egg survivorship.

Iverson JB, Ewert MA. Physical characteristics of reptilian eggs and a comparison with avian eggs. Egg Incubation: Its Effect on Embryonic Development in Birds and Reptiles. Cambridge University Press, New York, New York, USA. 1991 Dec 5:87-100.

Mitchell NJ, Rodriguez N, Kuchling G, Arnall SG, Kearney MR. Reptile embryos and climate change: modelling limits of viability to inform translocation decisions. Biological Conservation. 2016 Dec 1;204:134-47. 
Packard GC, Tracy CR, Roth JJ. The physiological ecology of reptilian eggs and embryos and the evolution of viviparity within the Class Reptilia. Biological Reviews. 1977 Feb;52(1):71-105.

Packard MJ, DeMarco VG. Eggshell structure and formation in eggs of oviparous reptiles. Egg Incubation: Its Effect on Embryonic Development in Birds and Reptiles. Cambridge University Press, New York, New York, USA. 1991 Dec 5:53-69.

Packard GC. Water relations of chelonian eggs and embryos: is wetter better? American Zoologist. 1999 Apr 1;39(2):289-303.

Furthermore, "bet hedging" could equally be important in abiotic (temperate) driven environments as in biotic (interactions) driven environments. Actually, a biotic environment could be more variable and unpredictable (see Moya-Laraño 2010 Open Ecol. J. 3:1-10). More eggs with latitude go indeed against a pattern for higher mortality in the tropics. However, this could merely reflect that selection is targeting egg size in the tropics (larger eggs could help offspring escaping stronger predation pressure in the tropics) and that a fundamental egg-size/egg-number trade-off makes then fewer eggs to be laid in the tropics (see Verdeny-Vilalta et al. 2015 J. Evol. Biol. 28:1225-1233 for a similar pattern). Of course, you the explain later in the text that the shell may make a big difference for predation. Is that the case also for turtle-lings? I see you refer to this issue later on in the text and indeed adults are better protected, thus.

This hypothesis seems very plausible according to what we know. But please, do explicitly refer to the egg-size/egg-number trade-off explicitly, not just implicitly as you do here. "In addition, Moll and Moll [12] concluded that temperate turtle species typically have small egg size to speed development as an adaptation to short incubation times in temperate zone [32]. As such, temperature zone turtles may have evolved to produce smaller egg size with larger clutch size than tropical turtle species."

Our reply: We have included egg-size/egg-number trade off specifically as follows

"Additionally, clutch mass (number of eggs $x$ egg size) can also vary with latitude[33, 41], further studies are necessary to examine how egg size correlates to differences in population growth rates, especially as egg size has been shown to be an important predictor of age at sexual maturity $[32,33] . "$.......

"The interaction between age at sexual maturity and latitude observed in this study is also in agreement with the earlier studies [62-64]."

please change it with

"The relationship between age at sexual maturity and latitude observed in this study is also in agreement with the earlier studies [62-64]."

you are not testing statistical interactions, which mean rather the opposite (multiplicative vs additive effects).

Our reply: We have made the correction.

The following sentence is fundamentally incomplete:

"Large body size provides advantages for temperate turtle species to cope with unfavorable environment through increasing their fitness $[33,66]$. As a result, temperate turtle species require longer time to reach size at sexual maturity."

Our reply: We have rephrased as follows to provide a link to the following paragraph which deals with adult survival: "As a result, temperate turtle species require longer time to reach size at sexual maturity, but increased size may provide for increased adult survivorship [32]. 
Even though larger body sizes increase cold hardiness, to reach this body size turtles will have to face with longer periods of time (several seasons!), which increases the probability of death before reproduction and, in addition, they will have to go through all those body size stages that are more dangerous (in which they are more vulnerable). You are implicitly referring to Bergmann's and inverse Bergmann's rule here. Please, do check a bit the extensive recent body of literature on this issue and discuss the explanations researchers have offered for what it may be occurring in ectotherms. A temperature constraint to reach maturation in a single season may be more appropriate as an explanation for the increase in large body size with latitude, I think. furthermore, this part "species to cope with unfavorable environment through increasing their fitness" is a circular argument. You mean that body size is larger because it provided a fitness advantage in the (evolutionary) past? increasing the fitness to cope with the unfavorable environment is biologically non-sense as fitness is an (evolutionary meaningful) response. Please change accordingly. Our reply: We have extensively revised this paragraph on page 23 (L) to clarify the text following the Editors suggestions.

For more information on how to upload your revised submission, see our video: http://blogs.plos.org/everyone/2011/05/10/how-to-submit-your-revised-manuscript/

If you choose not to submit a revision, please notify us.

Yours sincerely, Jordi Moya-Larano Academic Editor PLOS ONE

Journal requirements:

When submitting your revision, we need you to address these additional requirements.

Please ensure that your manuscript meets PLOS ONE's style requirements, including those for file naming. The PLOS ONE style templates can be found at http://www.plosone.org/attachments/PLOSOne_formatting_sample_main_body.pdf and http://www.plosone.org/attachments/PLOSOne_formatting_sample title_authors_affiliations.pdf

** It was noted by our internal staff that Figure 2 in your manuscript have been previously copyrighted.

Our reply: The revised version has figures that are fully compliant with plosone copyright guidelines. We clarify this in the figure legend as follows: "Fig 2. Distribution of freshwater turtle studies. Geographic distribution of data on freshwater turtle life history traits obtained from the literature ( S1 Table) to estimate capacity for sustainable harvest in freshwater turtles. Color of study locations represent the latitudinal distribution of the study species. Dashed horizontal lines show Tropic of Cancer and Tropic of Capricorn. The background map was obtained from the 1:110m Natural Earth country and geographic lines maps (http://www.naturalearthdata.com)." 
Should your paper be accepted, all images will published under PLOS' CC BY 4.0 license, which means that they will be freely available online, and any third party is permitted to access, download, copy, distribute, and use these materials in any way, even commercially, with proper attribution. For more information, see our Figure guidelines:

http://www.plosone.org/static/figureGuidelines\#policies

With regards to the previously copyrighted figures in your submission, we require you to either present written permission from the copyright holder to publish these figures, or remove the figures from your submission.

Our reply: The revised version has figures that are fully compliant with plosone copyright guidelines. We clarify this in the figure legend as follows: "Fig 2. Distribution of freshwater turtle studies. Geographic distribution of data on freshwater turtle life history traits obtained from the literature ( S1 Table) to estimate capacity for sustainable harvest in freshwater turtles. Color of study locations represent the latitudinal distribution of the study species. Dashed horizontal lines show Tropic of Cancer and Tropic of Capricorn. The background map was obtained from the 1:110m Natural Earth country and geographic lines maps (http://www.naturalearthdata.com)."

1. To seek permission from the original copyright holder of Figure 2 to publish it under the specific Creative Commons Attribution License (CCAL), CC BY 4.0, we recommend that you contact the original copyright holder with the following text:

"I request permission for the open-access journal PLOS ONE to publish XXX under the Creative Commons Attribution License (CCAL) CC BY 4.0 (http://creativecommons.org/licenses/by/4.0/). Please be aware that this license allows unrestricted use and distribution, even commercially, by third parties. Please reply and provide explicit written permission to publish XXX under a CC BY license."

Please upload the granted permission to the manuscript as a supporting information file. In the figure caption of the copyrighted figure, please include the following text: "Reprinted from [ref] under a CC BY license, with permission from [name of publisher], original copyright [original copyright year]."

2. If you are unable to obtain permission from the original copyright holder, please either i) remove the figure or ii) supply a replacement figure that complies with the CC BY 4.0 license, which can be for illustrative purposes only. Please check copyright information on all replacement figures and update the figure caption with source information. If applicable, please specify in the figure caption text when a figure is similar but not identical to the original image, and is therefore for illustrative purposes only.

3. It was noted that the figure(s) in question contains a map or satellite image. PLOS ONE is unable to publish previously copyrighted maps or satellite images, or images created using proprietary data. For these reasons, we cannot publish images generated by Google software (Google Maps, Street View, and Earth). If the content of the manuscript depends on the use of Google software, you may need to provide replacement images that are representative of the Google-generated images. The following resources for replacing copyrighted map figures may be helpful:

OpenStreetMap (data, but not generated images, are open): http://www.openstreetmap.org/ 
USGS National Map Viewer (public domain): http://viewer.nationalmap.gov/viewer/

The Gateway to Astronaut Photography of Earth (public domain):

http://eol.jsc.nasa.gov/sseop/clickmap/

Maps at the CIA (public domain): https://www.cia.gov/library/publications/the-worldfactbook/index.html and https://www.cia.gov/library/publications/cia-maps-publications/index.html

NASA Earth Observatory (public domain): http://earthobservatory.nasa.gov/

USGS EROS (Earth Resources Observatory and Science (EROS) Center) (public domain): http://eros.usgs.gov/\#

Grass GIS (geographic information system) analysis software (data, but not generated images, are open): http://grass.osgeo.org/

Grass GIS (geographic information system) analysis software (data, but not generated images, are open): http://grass.osgeo.org/

Our reply: The revised version has figures that are fully compliant with plosone copyright guidelines. We clarify this in the figure legend as follows: "Fig 2. Distribution of freshwater turtle studies. Geographic distribution of data on freshwater turtle life history traits obtained from the literature ( S1 Table) to estimate capacity for sustainable harvest in freshwater turtles. Color of study locations represent the latitudinal distribution of the study species. Dashed horizontal lines show Tropic of Cancer and Tropic of Capricorn. The background map was obtained from the 1:110m Natural Earth country and geographic lines maps (http://www.naturalearthdata.com)." 
Reviewers' comments:

Reviewer's Responses to Questions

\section{Comments to the Author}

1. Is the manuscript technically sound, and do the data support the conclusions?

The manuscript must describe a technically sound piece of scientific research with data that supports the conclusions. Experiments must have been conducted rigorously, with appropriate controls, replication, and sample sizes. The conclusions must be drawn appropriately based on the data presented.

Reviewer \#1: Yes

Reviewer \#2: Yes

2. Has the statistical analysis been performed appropriately and rigorously?

Reviewer \#1: Yes

Reviewer \#2: No

3. Does the manuscript adhere to the PLOS Data Policy?

Authors must follow the PLOS Data policy, which requires authors to make all data underlying the findings described in their manuscript fully available without restriction. Please refer to the author's Data Availability Statement in the manuscript. All data and related metadata must be deposited in an appropriate public repository, unless already provided as part of the submitted article or supporting information. If there are restrictions on the ability of authors to publicly share data-e.g. privacy or use of data from a third party-these reasons must be specified.

Reviewer \#1: Yes

Reviewer \#2: Yes

4. Is the manuscript presented in an intelligible fashion and written in standard English?

PLOS ONE does not copyedit accepted manuscripts, so the language in submitted articles must be clear, correct, and unambiguous. Any typographical or grammatical errors should be corrected at revision, so please note any specific errors here. 
Reviewer \#1: Yes

Reviewer \#2: Yes

\section{Review Comments to the Author}

Please use the space provided to explain your answers to the questions above. You may also include additional comments for the author, including concerns about dual publication, research ethics, or publication ethics. (Please upload your review as an attachment if it exceeds 20,000 characters)

Reviewer \#1: This is a well written and appropriately analyzed manuscript about freshwater turtle sustainability. I have several minor comments that are worth mentioning in the manuscript: Although extensive amount of literature has been cited that shows overall understanding of turtle natural history, there are several articles that have been recently published and that are relevant to this article:

1. In the introduction in the second paragraph, the authors should mention that although the greatest pressure on turtle harvest occurs in tropical areas, these high pressures can lead to regional population collapse and as a consequence create pressures in other regions of the world (Mali et al. 2014)

Mali, I., M.W. Vandewege, S.K. Davis, and M.R.J. Forstner. 2014. Magnitude of the freshwater turtle exports from the US: long term trends and early effects of newly implemented harvest management regimes. PLoSONE 9(1): e86478. doi:10.1371/journal.pone.0086478.

Our reply: Based on the helpful comments from the Editor and reviewers we have extensively revised and updated the literature cited. We have included in the revised text as follows "Additionally, unsustainable exploitation in tropical areas can also lead to regional population collapse and as a consequence create pressures in other regions of the world [24]."

2. Discussion paragraph 6- In talking about risks of harvesting adults and juveniles, the study of Zimmer-Shaffer et al. 2014 should also be mentioned.

Zimmer-Shaffer, S.A., J.T. Briggler, and J.J. Millspaugh. 2014. Modeling the effects of commercial harvest on population growth of river turtles. Chelonian Conservation and Biology 13(2):227-237. Our reply: We have added as follows "In addition, similar to previous studies [29, 30, 34, 74, 85-88], high adult and juvenile survival rates are estimated to be critical to maintain population stability due to their relatively greater contribution to population recruitment than other life stages [34]."

Additional minor comments:

Citation [45] is missing in the body of the article. Please address

Our reply: Based on the helpful comments from the Editor and reviewers we have extensively revised and updated the literature cited. We believe references and citations are consistent.

Abstract- "Turtles at low latitudes (tropical zones) exhibit similar adult survival rates...."

Delete "similar adult survival rates"

Our reply: Corrected as suggested. 
Introduction, Paragraph 2 and 3- Em dash was used for "15-18" and "25-27" citation and in the rest of the article hyphen was used.

Our reply: We have carefully revised all formatting in the text and references.

Introduction, Paragraph 3- Last citation could be fixed from [24,29-29] to [24,29]

Our reply: We have carefully revised all formatting in the text and references.

Results, Paragraph 1- In the last sentence replace "Just" with "Only" and ";" with "while" Our reply: Corrected as suggested.

Discussion, Paragraph 5- delete "only" in the sentence "It is important to note....."

Our reply: Corrected as suggested. We have extensively revised the Discussion to improve flow and clarity.

Discussion, Paragraph 6- Correct the sentence "Egg harvest is may be....." to "Egg harvest may be more feasible..."

Our reply: Corrected as suggested. We have extensively revised the Discussion to improve flow and clarity.

In Paragraph 6, it would be worth noting that the potential of farming turtles in the tropics for meat markets should be further explored as it may represent a potential decrease in pressures on wild populations (Mali et al. 2015)

Mali, I., H.H. Wang, W.E. Grant, M. Feldman, and M.R.J. Forstner. 2015. Modeling commercial freshwater turtle production on US farms for pet and meat markets. PLoSONE 10(9): e0139053. doi: 10.1371/journal.pone.0139053.

Our reply: Included as follows: "Considering these results, harvesting wild adults would appear to present a high risk of causing population declines whether in the temperate or tropical regions, reinforcing the need to develop appropriately enforced alternate management options such as farming of captive reared turtles for meat [89]."

Thank you for addressing these comments.

Reviewer \#2: This is an interesting piece of work focused on the potential of sustainable harvest as a conservation measure for turtles, comparing the life history traits and demographic sensitivities of temperate vs. tropical species. Despite similar studies focused on particular species exist, none has previously investigated the harvest potential of freshwater turtles at a global scale. Research objectives are clear, the literature review effort behind is impressive and the manuscript is well 
written overall. However, I think the manuscript still needs major improvements for it to be publishable, especially regarding the methodology and presentation of results.

Major concerns:

Methodological coherence: the main aim of this study is to compare demographic parameters of tropical vs temperate freshwater turtle species. This is done when describing life history parameters and when projecting population growth but not when constructing the GLMMs; instead, all data is analysed together. Why not conducting two separate analysis? I suggest to conduct one for tropical species and another for temperate ones and compare results regarding bioclimatic effects on each group. This could help show the differences/similarities between tropical and temperate taxa more clearly and focus the discussion on these comparison.

Our reply: This is explicitly included via including latitudinal zones in the revised analysis.

Variables chosen in GLMMs: the authors choose latitudinal and bioclimatic variables as fixed effects in their models, but the hypotheses behind this decision or their expected effects on life history parameters are not described and should be presented in the introduction or in the methods section.

Our reply: We have extensively revised the Methods to clarify variable choice.

Also, there could be some redundancy as latitude may be a proxy of annual temperature, so you seem to be testing the same hypotheses or effects twice in your analysis. Indeed, results (beta slopes) of the model considering latitude as continuous variable and those of the bioclimatic model have identical interpretation (they both show significant temperature effects on clutch size, clutch frequency and age at sexual maturity). I suggest removing the continuous latitude variable and keep only continuous bioclimatic variables in the analysis.

Our reply: We have now included two bioclimatic variables that are only weakly correlated with latitude. This choice is detailed in the Methods and the updated results presented in Table 2 and Table 3. This enables us to focus the Discussion on the effects of temperature.

Missing information and omitted findings: It seems to me that some relevant information is missing regarding the population projections and the results of the analysis with GLMMs. What was the initial population size chosen in the population projection models? Do you consider a stable age distribution (SAD)? What is the proportion of individuals in each stage of the population (egg, juvenile, adult)?

Our reply: Yes, we use a stable stage distribution. We have added these details to Methods (p l) as follows: "The model consisted of egg, juvenile, and adult stages (Fig 1) projected with a stable stage distribution (initial population of 1000, allocated in proportions of $0.544,0.401$, 0.055 to egg, juvenile and adult stages respectively)."

In the methods section, annual precipitation (bio12) is mentioned as one of the variables considered in the GLMMs, but it never appears in tables 2 and 3 and only results for the temperature variable (bio1) are shown. I could not find any explanation for that in the manuscript, except that precipitation variables were not as good as temperature variables (but no statistical significance values nor beta slopes are given). All models constructed (including those receiving low statistical support) must be presented in the results tables as well as the estimated parameters (beta slopes).

Our reply: The revised version includes new bioclimatic variables bio10 and bio17 and the updated results (including beta slopes) are presented in Table 2 and Table 3. 


\section{Minor comments}

Line and page numbers are missing in the manuscript, please add them prior to re-submission in order to ease future reviews.

Our reply: we have added line and page numbers.

The manuscript is well written but I have detected some errors in spelling ("meant" instead of "mean") and in word use ("temperature" when referring to "temperate" species) that indicates correct spelling and redaction should be checked in the manuscript.

Our reply: we have carefully reviewed the text to ensure such typos have been corrected.

Table 2: I suggest to remove this table and present it as supporting information, given that interesting beta values are already given in the text (results section) and the relevant information regarding the GLMMs analysis is provided in table 3.

Our reply: We thank the reviewer for the suggestion. We prefer to retain Table 2 in the main text. We believe this facilitates a clear text for readers as Table 2 is heavily cited in the Results and we therefore prefer to retain so readers do not have to go back and forth to Supplemental Material to examine these important results. But we are happy to follow editorial guidance regarding the need to reorganize the presentation of results in the tables.

Table 3: Model notation should change and be less "R-like". Readers are more interested in knowing the hypotheses behind each model and less in the R code used, so models should be named in the light of the hypotheses being tested each time (i.e. latitude effect, temperature effect etc.).

Our reply: Following this helpful suggestion we have updated both Table 2 and Table 3 to improve clarity for readers.

Table 3: why only 2 models for Adult survival?

Our reply: As explained in the Methods of the original submission a reduced number of models were tested with adult survival due to the limited sample size. In the revised version we have updated and expanded our literature search and have been able to increase the number of studies with adult survival. This increased sample size has now enabled us to update adult survival with the full model set.

Table 3: this table shows many information criteria for model selection, but only the AIC is defined in the methods section. Alternative criteria such as Log-likelihood or BIC (Bayesian?) are not defined in the methods nor in the table legend but are shown in the table anyway (Why?). I suggest to remove them.

Our reply: We have added selection criteria definitions with citations in the Table 3 footnote to clarify for readers. It is standard (best) practice to include multiple selection criteria. Selection 
is via AICc (as explained in the methods) and we add additional criteria so that interested readers can evaluate the results and conclusions in more detail. In our case the multiple criteria show the same genial patterns, which provide additional confidence as to the robustness of the analysis and validity of the conclusions. These are all standard selection criteria and as we do not deal with any evaluation of statistical selection criteria, we therefore feel there is no need to add any further details. But we are happy to follow editorial guidance regarding the need for any additional methodological clarification.

Also, there may be some redundancy between AIC weight and delta AIC as both tend to highlight the best supported model, so one of them could be also removed. Deviance values might be removed too as the AIC is already computed using the deviance.

Our reply: We now retain variables included in a confidence set of models. This approach explicitly uses AIC weight which is obtained by ordering variables by AICc value. We feel including both AIC weight and delta AIC enables readers to fairly evaluate our results and the robustness of the conclusions, but we are happy to follow editorial guidance regarding the need for any additional methodological clarification.

Table 3: for clutch frequency, the bioclimatic model (bio1) is the best one, but the latitude model is also well supported, with almost the same AIC weight (0.45 vs. 0.46). I think this shows that latitudinal and temperature variables are redundant (see major comments). If not, I think this result deserves to be mentioned in the manuscript and probably discussed.

Our reply: Based on this and the previous comments we have updated the bioclimatic variables and the analysis, Results and Discussion. For example we now retain all variables included in a confidence set of models.

Figure 3: It shows the same information as in table 2. I suggest to remove table 2 and upload it as supporting information (see previous comment on table 2 )

Our reply: We have updated both Figure 3 and Table 2, and feel there is now no duplication of results. We prefer to retain Table 2 in the main text. We believe this facilitates reading of the text for readers as Table 2 is heavily cited in the Results and we therefore prefer to retain so readers do not have to go back and forth to Supplemental Material to examine these important results. But we are happy to follow editorial guidance regarding the need to reorganize the presentation of results in the tables.

Figure 5: fecundity could be more reduced in tropical than in temperate species without causing negative population growth. This is the clearest result I see here, but it is not mentioned in the results nor discussed in the manuscript. Does not fecundity determine egg production? You should discuss the implications of this finding on the capacity to sustain harvest.

Our reply: We thank the reviewer for the suggestion. It is rather like the case of chicken and egg - the question as to whether turtle species are more fecund because of increased egg production or has increased egg production because it is more fecund remains unanswered. Fecundity is not heavily discussed as it is unlikely to be suitable for any sort of conservation management action. Our focus is on exploring the sustainable harvest of turtle species which 
directly targets survival of the different stages. Fecundity is obviously important and included in the projection matrix but is not normally of interest for any management actions. We prefer to retain Discussion text focused on the sustainable harvest of different life stages in tropical and temperate turtles and are happy to follow editorial guidance for the need of any additional content in the Discussion. 